\title{
The Evaluation of Estoque Model 1990 in Land/Sea Breezes Occurrence over Northern Persian Gulf
}

\author{
S. Hassanzadeh, ${ }^{1}$ A. Sedaghatkerdar, ${ }^{2}$ and M. Soyuf Jahromi ${ }^{3}$ \\ ${ }^{1}$ Department of Physics, University of Isfahan, Isfahan 81744, Iran \\ ${ }^{2}$ Meteorology Department, Atmospheric Science and Meteorological Research Center, P.O. Box 14965, 114 Tehran, Iran \\ ${ }^{3}$ Physical Oceanography Department, Khoramshahr Marine Science and Technology University, Khoramshahr 669, Iran \\ Correspondence should be addressed to S. Hassanzadeh, shz@sci.ui.ac.ir
}

Received 5 December 2010; Accepted 17 March 2011

Academic Editor: Hann-Ming Henry Juang

Copyright (๑) 2011 S. Hassanzadeh et al. This is an open access article distributed under the Creative Commons Attribution License, which permits unrestricted use, distribution, and reproduction in any medium, provided the original work is properly cited.

\begin{abstract}
This is a mesoscale modeling study of land/sea breeze in the vicinity of Bushehr, Iran which is on the coast of the Persian Gulf. Two days in September, 2002 are studied using the model presented in Estoque Model (1990) (hereafter referred to as EsM90). The EsM90 produces a realistic day-night wind field somewhat in agreement with observations provided by the Port and Shipping Organization of Iran. The study demonstrates that the model has a 3-hour delay predicting the time of the maximum of sea breeze, but accurately predicts when the end of the sea breeze occurs. Accurate estimates near mountains at the edge of the modeled region require a more complex simulation. The study shows that a reliable modeling of a complicated coastal environment like Bushehr not only depends on land/sea breezes but also on elevations and prevailing winds. This dependence is especially important when local thermal forcings are weak, for example, during late afternoon and at night.
\end{abstract}

\section{Introduction}

The Sea Breeze is a common mesoscale phenomenon during the summer months in many coastal areas and has been observed and documented since ancient times [1]. A typical sea breeze may penetrate $50 \mathrm{~km}$ or more inland, though its strength depends on the terrain over which it travels. At night the temperature contrast between land and sea reverses and the air over the sea is warmer. This generates a land breeze that blow in the opposite direction to the sea breeze [2]. Sea breeze speed usually ranges between 6 and $10 \mathrm{~m} / \mathrm{s}$ and from 3 to $5 \mathrm{~m} / \mathrm{s}$ for a land breeze. The land breezes tend to be weaker than sea breezes. The on/off shore extend of the sea breeze is about $10-20 \mathrm{Km}$ [3].

A typical land/sea breeze circulation is seldom completely free of the effects regarding atmospheric factors and nonatmospheric factors. Of the atmospheric factors, the gradient of the prevailing wind $[4-7]$, the stability $[5,7]$, the cloudiness and humidity $[2,7]$, and the season [5], and the nonatmospheric ones, the coriolis force and latitudes [8] and land surface characteristics are most important. Land surface characteristics may influence the sea breeze circulation in three main ways: the topography [9-15], the vegetation cover, and soil properties such as soil type and soil moisture $[9,16-18]$, and finally the coastline shape $[19,20]$. Among all factors, the prevailing wind is much more important (e.g., [21]). They showed that the characteristics of the sea breeze circulation over southern and east-central Florida are sensitive to synoptic scale wind direction and speed.

On the other hand, a variety of tools, including aircraft measurements [22], pilot balloons (e.g., [23]), satellite images (e.g., [24]) and Doppler radar (e.g., [25]), have been utilized to investigate the thermodynamic and kinematical characteristics and structures of the sea breeze. Laboratory studies (e.g., [26]) and analytical models (e.g., [27]) have contributed extensively to our present knowledge. The sea breeze has also been studied with the help of two-dimensional models (e.g., $[4,28,29])$ and three-dimensional numerical models [21].

As studies developed, it is recognized that meteorological models are essential to understanding pollutant transport, and, therefore, there have been many studies of land/sea 
breezes to analysis the dispersion of pollutants (e.g., [30]). Moreover, sea breezes have long been known to modify water motion in coastal regions. In particular, Hyder et al. [31], Chen and Xie [32], O'Brien et al. [33], Craig [34, 35], and Rosenfeld [36] discussed the impact of sea breeze on diurnal currents in shelf seas. So, studying land/sea breezes can help understanding some features at coastal area. To continue this way, we have provided a numerical two-dimensional model to simulate land/sea breeze at a coastal area of the Persian Gulf.

\section{Model Description}

In this study, we use the Estoque's Model 1990, (EsM90), which had been defined for a complex terrain. In this study we use the model in Estoque [28] (EsM90) which permits specifying a complex terrain. Although, more complex and accurate models have been developed for simulating terraininduced mesoscale circulations, but as expected, complex models are generally more accurate than the simpler ones, but, the simpler model has the obvious advantage of requiring smaller computers for integrating the model equations. In addition, the EsM90 equations can incorporate the effect of nonuniformities in surface temperature, roughness, and terrain elevation to some extent.

2.1. Model Equations [28]. Primitive model equations use a terrain-following coordinate in the vertical $(\sigma)$ and the usual coordinates, $x$ and $y$. The vertical coordinate is defined as

$$
\sigma \equiv \frac{z-h}{D-h} .
$$

Here, $z$ is the height of a point, $h$ is the height of the terrain, and $D$ is the top of the physical model. The primary equations of the model are the momentum equations, the thermodynamic energy equation, and hydrostatic equation.

$$
\begin{aligned}
\frac{\partial u}{\partial t}= & -u \frac{\partial u}{\partial x}-v \frac{\partial u}{\partial y}+f v-\theta \frac{\partial \phi}{\partial x}-g \frac{\partial h}{\partial x}-K_{1} u-K_{2}\left(u-u_{D}\right) \\
& +\frac{\partial}{\partial x}\left(K_{x} \frac{\partial u}{\partial x}\right)+\frac{\partial}{\partial y}\left(K_{y} \frac{\partial u}{\partial y}\right)+\left(\frac{\partial u}{\partial t}\right)_{s}, \\
\frac{\partial v}{\partial t}= & -u \frac{\partial v}{\partial x}-v \frac{\partial v}{\partial y}-f u-\theta \frac{\partial \phi}{\partial y}-g \frac{\partial h}{\partial y}-K_{1} v-K_{2}\left(v-v_{D}\right) \\
& +\frac{\partial}{\partial x}\left(K_{x} \frac{\partial v}{\partial x}\right)+\frac{\partial}{\partial y}\left(K_{y} \frac{\partial v}{\partial y}\right)+\left(\frac{\partial v}{\partial t}\right)_{s}, \\
\frac{\partial \theta}{\partial t}= & -u \frac{\partial \theta}{\partial x}-v \frac{\partial \theta}{\partial y}+\frac{\partial}{\partial x}\left(K_{x} \frac{\partial \theta}{\partial x}\right)+\frac{\partial}{\partial y}\left(K_{y} \frac{\partial \theta}{\partial y}\right) \\
& +\left(\frac{\partial \theta}{\partial t}\right)_{R}+\left(\frac{\partial \theta}{\partial t}\right)_{\omega}+\left(\frac{\partial \theta}{\partial t}\right)_{Q}
\end{aligned}
$$

where $u$ and $v$ are the components of the velocity along $x$ and $y, \theta$ is the potential temperature, $f$ is the coriolis parameter, and $g$ is gravity. The quantities $u D$ and $v D$ are the wind component at level $D$. The quantity $\phi$ is defined as follows:

$$
\phi=c_{P}\left(\frac{P}{P_{0}}\right)^{K},
$$

$K=R / c_{P} ; R=$ gas constant for air; $c_{P}=$ specific heat at constant temperature; $P_{0}=1000 \mathrm{mb}$. The hydrostatic equation is

$$
\frac{\partial \phi}{\partial \sigma}=\frac{-g}{\theta}(D-h) .
$$

All the above model equations were written in height coordinate.

In the two momentum equations, there are four physical processes which are parameterized, corresponding to the last five terms:

(a) surface or skin friction: $K_{1} u$ and $K_{1} v$;

(b) momentum exchange between the surface and the upper level, $D, K_{2}\left(u-u_{D}\right)$ and $K_{2}\left(v-v_{D}\right)$;

(c) horizontal diffusion of momentum,

$$
\frac{\partial}{\partial x}\left(K_{x} \frac{\partial u}{\partial x}\right)+\frac{\partial}{\partial y}\left(K_{y} \frac{\partial u}{\partial y}\right), \quad \frac{\partial}{\partial x}\left(K_{x} \frac{\partial v}{\partial x}\right)+\frac{\partial}{\partial y}\left(K_{y} \frac{\partial v}{\partial y}\right) ;
$$

(d) slope wind generation, $\partial u / \partial t)_{s}$ and $\left.\partial v / \partial t\right)_{s}$.

The first item above, $K_{1} u$ and $K_{1} v$, represents the tendency of ground friction to reduce the surface wind speed. The expression for the resistance coefficients, $K_{1}$, is given by

$$
K_{1} \equiv \frac{C_{D}|V|}{(D-h)}, \quad \text { where }|V|=\left(u^{2}+v^{2}\right)^{1 / 2},
$$

The drag coefficient, $C_{D}$, depends on the thermal stability; the formula for $C_{D}$, is presented later in the text. The 2 nd item, $K_{2}\left(u-u_{D}\right)$ and $K_{2}\left(v-v_{D}\right)$, represents the vertical exchange of momentum between the surface and the layer above. This produces the surface wind maximum during the daytime due to vertical mixing. The expression for $K_{2}$ is $K_{2}=C_{m} V_{D}(1-S R i)\left(1+C_{n} h / D\right) / D$, where $C_{m}, S$, and $C_{n}$ are empirical constants. The value of these constants and other constants are given in Section 2.4. The quantity Ri is Richardson number. Its formula is presented on a later page. At the 3 rd item, horizontal diffusion of momentum, the $K_{x}$ and $K_{y}$ coefficients which are the eddy diffusion coefficients, vary horizontally according to the formulas,

$$
\begin{gathered}
K_{x}=C_{k}(\Delta x)^{2}\left[\left(\frac{\partial u}{\partial x}\right)^{2}+\left(\frac{\partial v}{\partial x}\right)^{2}\right]^{1 / 2}, \\
K_{y}=C_{k}(\Delta y)^{2}\left[\left(\frac{\partial u}{\partial y}\right)^{2}+\left(\frac{\partial v}{\partial y}\right)^{2}\right]^{1 / 2} .
\end{gathered}
$$

These expressions are based on a previous formulation by Smagorinsky et al. [37]. The constant $C_{k}$, is an empirical 


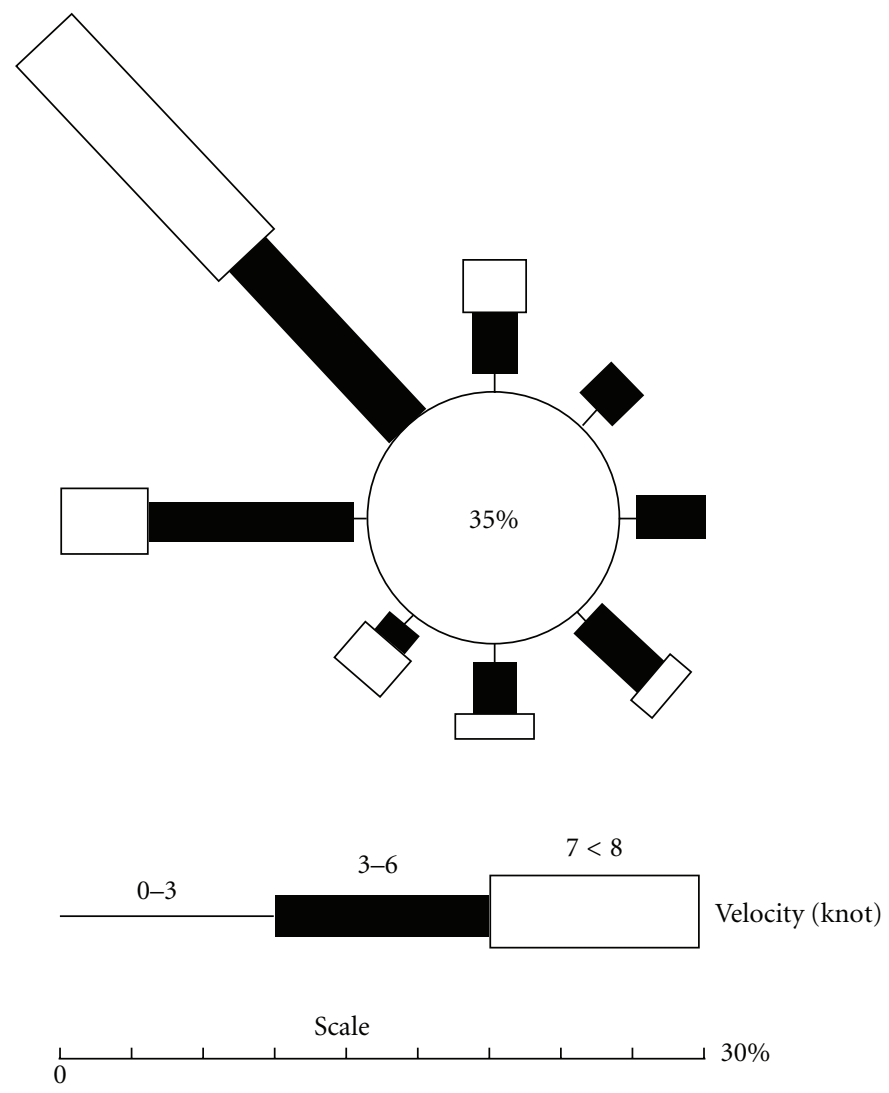

Figure 1: The diurnal wind rose of the synoptic Bushehr station from 1970 to 1995. It is provided from 26-year Bushehr synoptic station data, located at $28^{\circ} 59^{\prime} \mathrm{E}$ and $50^{\circ} 50^{\prime} \mathrm{N}$. It can easily be seen, the predominant wind is NW-SE wind (Shamal), adopted from Iran Meteorological Organization.

Table 1: Characteristics of land/sea breezes at different days of September 2002.

\begin{tabular}{|c|c|c|c|c|c|c|}
\hline Date & Starting time & Ending time & Durations (Hour) & Speed $(\mathrm{m} / \mathrm{s})$ & Depth $(\mathrm{m})$ & Horizontal extent $(\mathrm{km})$ \\
\hline 11th & 12 & 22 & 11 & 4.8 & 461 & 48 \\
\hline 12 th & 11 & 21 & 11 & 4.3 & 370 & 43 \\
\hline 13 th & 13 & 21 & 09 & 5.6 & 627 & 56 \\
\hline 14 th & 11 & 21 & 11 & 3.9 & 304 & 39 \\
\hline 16 th & 11 & 23 & 13 & 3.3 & 218 & 33 \\
\hline 17 th & 11 & 23 & 13 & 1.3 & 192 & 31 \\
\hline 18 th & 10 & 23 & 14 & 3.5 & 245 & 35 \\
\hline Mean & - & - & 11.7 & 3.8 & 289 & 38 \\
\hline
\end{tabular}
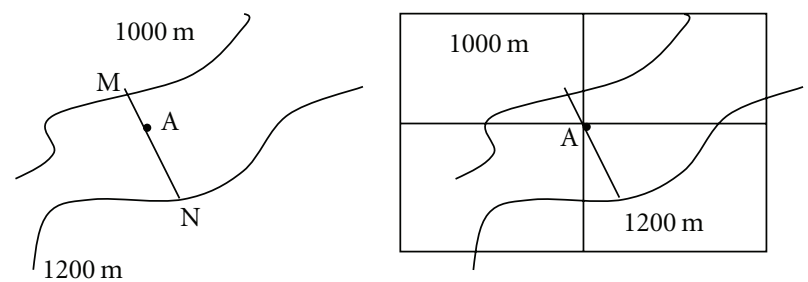

FIgURE 2: Inputting elevations to the grid points at the model.

quantity, while $\Delta x$ and $\Delta y$ are grid distances along the $x$ and the $y$-directions. The 4 th item, slope wind generation, represents the physical process which generates upslope motions during the daytime and downslope motions at night. The expression for $\partial u / \partial t)_{s}$ and $\left.\partial v / \partial t\right)_{s}$ is:

$$
\left(\frac{\partial u}{\partial t}\right)_{s}=C_{B} g \frac{\partial h}{\partial x} \frac{\left(\theta_{s}-\theta\right)}{\theta}, \quad\left(\frac{\partial v}{\partial t}\right)_{s}=C_{B} g \frac{\partial h}{\partial y} \frac{\left(\theta_{s}-\theta\right)}{\theta}
$$

Here, $C_{B}$, is an empirical constant while $\theta_{s}$ is the temperature of the ground surface.

Additionally, there are also four physical processes in the $\theta$ equation: 


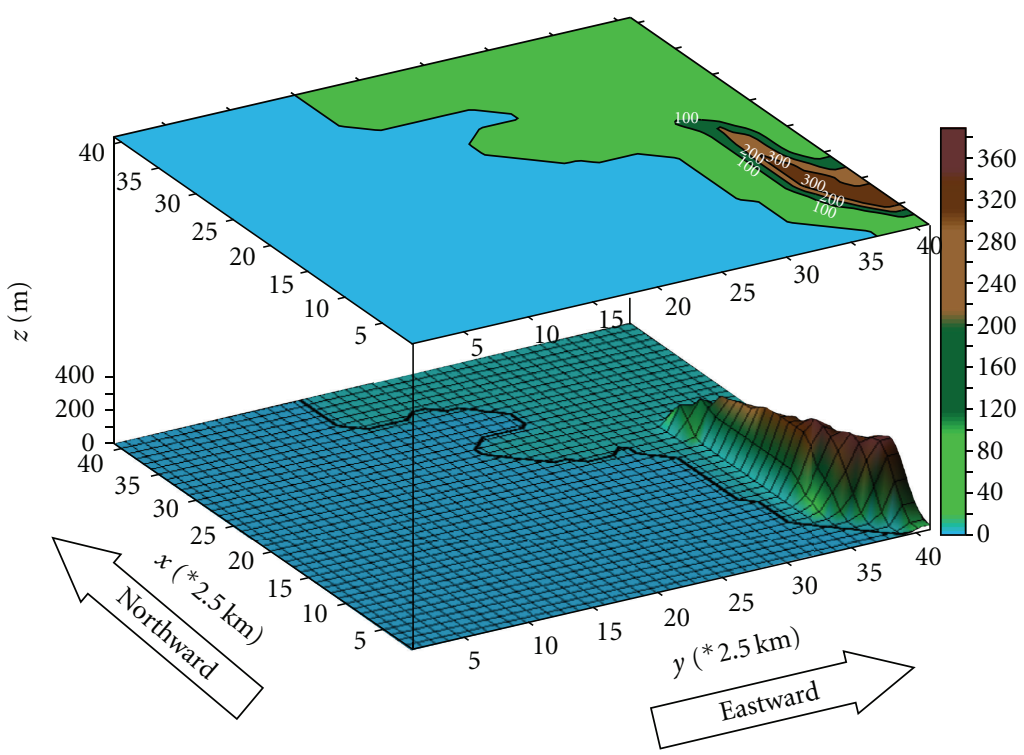

Figure 3: The 3D of terrain which is designed by Surfer 8 .

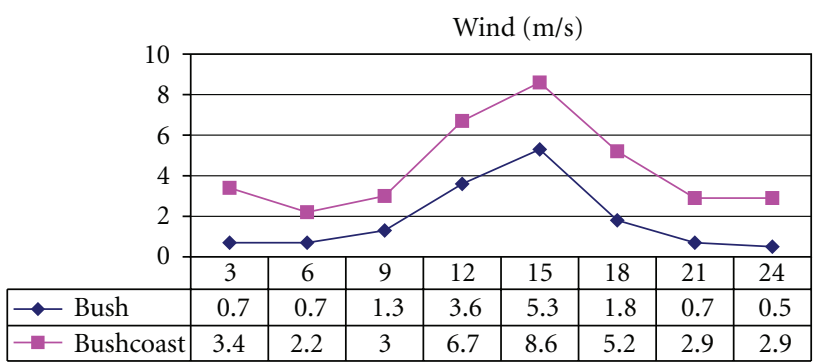

Figure 4: The mean 3-hour diagram of the wind speed at September 2002. It shows the actual Bushehr wind conditions for that month. The data adopted from the Synoptic Bushehr Station lactated at $28^{\circ} 59^{\prime} \mathrm{E}$ and $50^{\circ} 50^{\prime} \mathrm{N}$ and the Coastal Bushehr Station lactated at $28^{\circ} 54^{\prime} \mathrm{E}$ and $50^{\circ} 49^{\prime} \mathrm{N}$, Iran Meteorological Organization.

(a) horizontal diffusion of heat (the two terms involving $K_{x}$ and $K_{y}$ ).

(b) radiative temperature changes $(\partial \theta / \partial t)_{R}$. The expression for this term is based on the concept of Newtonian cooling. Thus, $(\partial \theta / \partial t)_{R}=C_{R}\left[0.9\left(T_{s}-T\right)+0.1\left(T_{D}-T\right)\right]$. Here, $C_{R}$, is an empirical constant while $T$ is temperature at surface anemometer level; $T_{s}$ is ground surface temperature, and $T_{D}$ is temperature at $Z=D$.

(c) temperature changes due to vertical motion, $(\partial \theta / \partial t)_{\mathrm{W}}$, for example, cooling due to expansion when the motion is upward; the formula for this term is

$$
\left(\frac{\partial \theta}{\partial t}\right)_{\mathrm{W}}=-K_{T} \frac{\theta_{D}-\theta}{D-h}(V \cdot \Delta h)+K_{C}\left(\theta_{D}-\theta\right)\left(\frac{\partial u}{\partial x}+\frac{\partial v}{\partial y}\right),
$$

the first term on the right-hand side represents the effect of orographically forced vertical motion; the second term represents the effect of vertical motions associated with

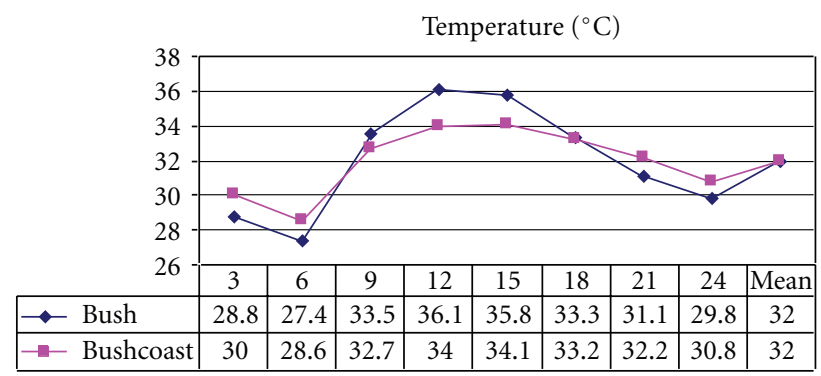

Figure 5: The mean 3-hour diagram of the temperature at September 2002. This figure shows the actual Bushehr air temperature at that month for starting Initial Conditions. The data adopted from the Synoptic Bushehr Station lactated at $28^{\circ} 59^{\prime} \mathrm{E}$ and $50^{\circ} 50^{\prime} \mathrm{N}$ and the Coastal Bushehr Station lactated at $28^{\circ} 54^{\prime} \mathrm{E}$ and $50^{\circ} 49^{\prime} \mathrm{N}$, Iran Meteorological Organization.

surface convergence over flat terrain; Here, $K_{T}$ and $K_{C}$ are empirical constants;

(d) temperature changes to the sensible heat flux from the earth surface, $(\partial \theta / \partial t)_{Q}$. In order to estimate this quantity, we assume $\theta(x, y, \sigma, t)=\bar{\theta}(\sigma)+\theta^{\prime}(x, y, \sigma, t)$, where $\bar{\theta}(\sigma)$ is the vertical variation of the prevailing large-scale potential temperature. Furthermore, we note that, at a particular point $(x, y)$ at any level, $\sigma,(\partial \theta / \partial t)_{Q, \sigma}=\left(\partial \theta^{\prime} / \partial t\right)_{Q, \sigma}$. We now make the important assumption that the vertical distribution of the heating is approximated by

$$
\left(\frac{\partial \theta^{\prime}}{\partial t}\right)_{Q_{\sigma}}=\left(\frac{1-\sigma}{1-\sigma_{a}}\right)^{n}\left(\frac{\partial \theta^{\prime}}{\partial t}\right)_{Q, a} .
$$

Here the subscript, $a$, refers to values at surface anemometer level; the exponent, $n$, is an empirical constant. This assumption is based primarily on experience, similar to the power law for wind profiles. From here on, we will drop the subscript, $a$, from $\left(\partial \theta^{\prime} / \partial t\right)_{Q_{\sigma}}$ for the sake of simplicity in 


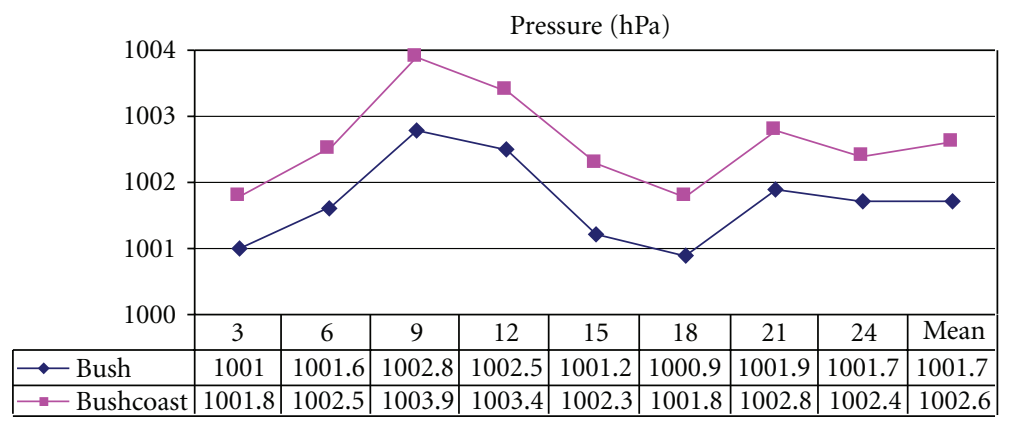

Figure 6: The mean 3-hour diagram of the pressure at September 2002. It illustrates the actual Bushehr pressure at that month for initial conditions. The data adopted from the Synoptic Bushehr Station lactated at $28^{\circ} 59^{\prime} \mathrm{E}$ and $50^{\circ} 50^{\prime} \mathrm{N}$ and the Coastal Bushehr Station located at $28^{\circ} 54^{\prime} \mathrm{E}$ and $50^{\circ} 49^{\prime} \mathrm{N}$, Iran Meteorological Organization.

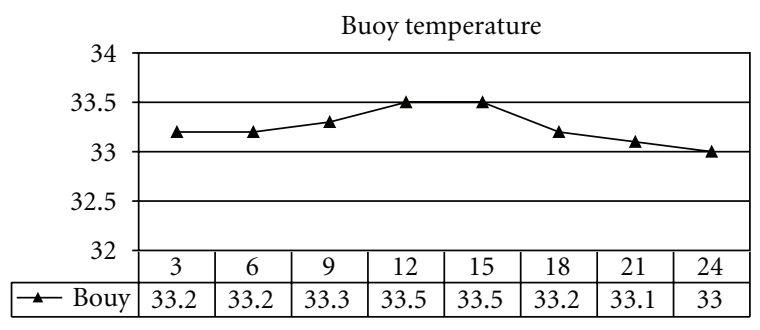

FIgURE 7: The mean 3-hour diagram of the buoy temperature over the sea surface at September 2002. It shows the Bushehr water temperature at that month. This figure helps us to select the best water temperature for initial conditions. The data adopted from the Synoptic Bushehr Station lactated at $28^{\circ} 59^{\prime} \mathrm{E}$ and $50^{\circ} 50^{\prime} \mathrm{N}$ and the Coastal Bushehr Station lactated at $28^{\circ} 54^{\prime} \mathrm{E}$ and $50^{\circ} 49^{\prime} \mathrm{N}$, Iran Meteorological Organization.

notation. Having done that, we will now attempt to express $\left(\partial \theta^{\prime} / \partial t\right)_{Q}$ in terms of the sensible heat flux, $Q$, from the earth surface. In order to do this, the first step that is done is to integrate the equation above from the surface to the top of the domain. Thus,

$$
\int_{0}^{1}\left(\frac{\partial \theta^{\prime}}{\partial t}\right)_{Q, \sigma} d \sigma=\left(\frac{\partial \theta^{\prime}}{\partial t}\right)_{Q}\left(1-\sigma_{a}\right)^{-n} \int_{0}^{1}(1-\sigma)^{n} d \sigma .
$$

Performing the integration and then solving for $\left(\partial \theta^{\prime} / \partial t\right)_{Q}$, one gets

$$
\left(\frac{\partial \theta^{\prime}}{\partial t}\right)_{Q}=\left(1-\sigma_{a}\right)^{n}(n+1) \int_{0}^{1}\left(\frac{\partial \theta^{\prime}}{\partial t}\right)_{Q, \sigma} d \sigma .
$$

Note, however, that the integrand represents the total heating of air column due to sensible heat flux. Therefore, $\int\left(\partial \theta^{\prime} / \partial t\right)_{Q, \sigma} d \sigma=(Q /(D-h))$.

Combining this equation with the preceding one, one gets

$$
\left(\frac{\partial \theta^{\prime}}{\partial t}\right)_{Q}=\frac{(n+1)\left(1-\sigma_{a}\right)}{D-h} Q \approx \frac{n+1}{D-h} Q=\left(\frac{\partial \theta}{\partial t}\right)_{Q} .
$$

Finally, the heat flux $(Q)$ must be expressed in terms of $u$, $v, \sigma$, and the surface temperature, $\theta_{s}$. On the basis of the so-called bulk aerodynamic method, the formula is: $Q=$
$C_{D}\left(u^{2}+v^{2}\right)^{1 / 2}\left(\theta_{s}-\theta\right)$. The drag coefficient $\left(C_{D}\right)$ is, in turn, formulated in terms of Richardson number (Ri) and the roughness parameter $\left(Z_{0}\right)$, following a suggestion by Louis et al. [38]. The formula is

$$
\begin{aligned}
& C_{D}=\left\{\begin{array}{c}
\frac{C_{D N}}{\left[1+15 \mathrm{Ri}(1+5 \mathrm{Ri})^{1 / 2}\right]}, \quad \mathrm{Ri}>0, \\
C_{D N}\left\{\frac{1-15 \mathrm{Ri}}{\left[1+75 C_{D N}\left(-\mathrm{Ri} Z_{a} / Z_{0}\right)^{1 / 2}\right]}\right\}, \quad \mathrm{Ri} \leq 0,
\end{array}\right. \\
& C_{D N}=\left[\frac{k_{0}}{\ln \left(Z_{a} / Z_{0}\right)}\right]^{2}, \mathrm{Ri} \equiv \frac{Z_{a} g(\theta / \theta s-1)}{\left(u^{2}+v^{2}\right)} .
\end{aligned}
$$

Here, $k_{0}$ is the Karman constant, $Z_{a}$ is the height of the surface observations for wind and temperature. The quantity, $C_{D N}$, is the customary value of the drag coefficient for neutral stratification.

The last important aspect of the model formulation which will be discussed is determination of the geopotential of the surface anemometer level, $\phi_{a}$. This is done by integrating the hydrostatic equation from the top of the model domain $\left(\sigma_{D}\right)$ to the surface anemometer level $\left(\sigma_{a}\right)$. In connection with the integration, one has to specify the vertical distribution of $\theta^{\prime}$. For this purpose, we make the same power law assumption which was made previously. Thus, $\theta_{\sigma}^{\prime}=\theta_{a}^{\prime}\left[(1-\sigma) /\left(1-\sigma_{s}\right)\right]^{n}$. Again, we will drop the subscript, $a$, in $\theta_{a}$ (for simplicity of notation) with the understanding that $\theta$ refers to the surface anemometer level. We note further that: $\theta_{\sigma}=\theta_{\sigma}^{\prime}+\bar{\theta}(\sigma)$ with $\theta_{\sigma}^{\prime}$ given by the preceding formula. Substituting this in the hydrostatic equation, (4), and integrating, we get: $\phi \equiv \phi_{a}=\phi_{D}+$ $g(D-h)\left[\alpha-\left(\beta \theta^{\prime}\right) /(1-\sigma a)^{n}\right] ; \alpha \equiv \int_{\sigma_{a}}^{1}(1 / \theta(\sigma)) d \sigma$, and $\beta \equiv$ $\int_{\sigma_{a}}^{1}(1-\sigma)^{n} /[\theta(\sigma)]^{2} d \sigma$.

We have now finished the formulation of the model. All these information about EsM90 equations, the relationships between quantities and parameters are derived from Estoque [28].

2.2. Model Spatial and Temporal Situation. We choose Bushehr, Iran and its surrounding area (Figure 9) because of 


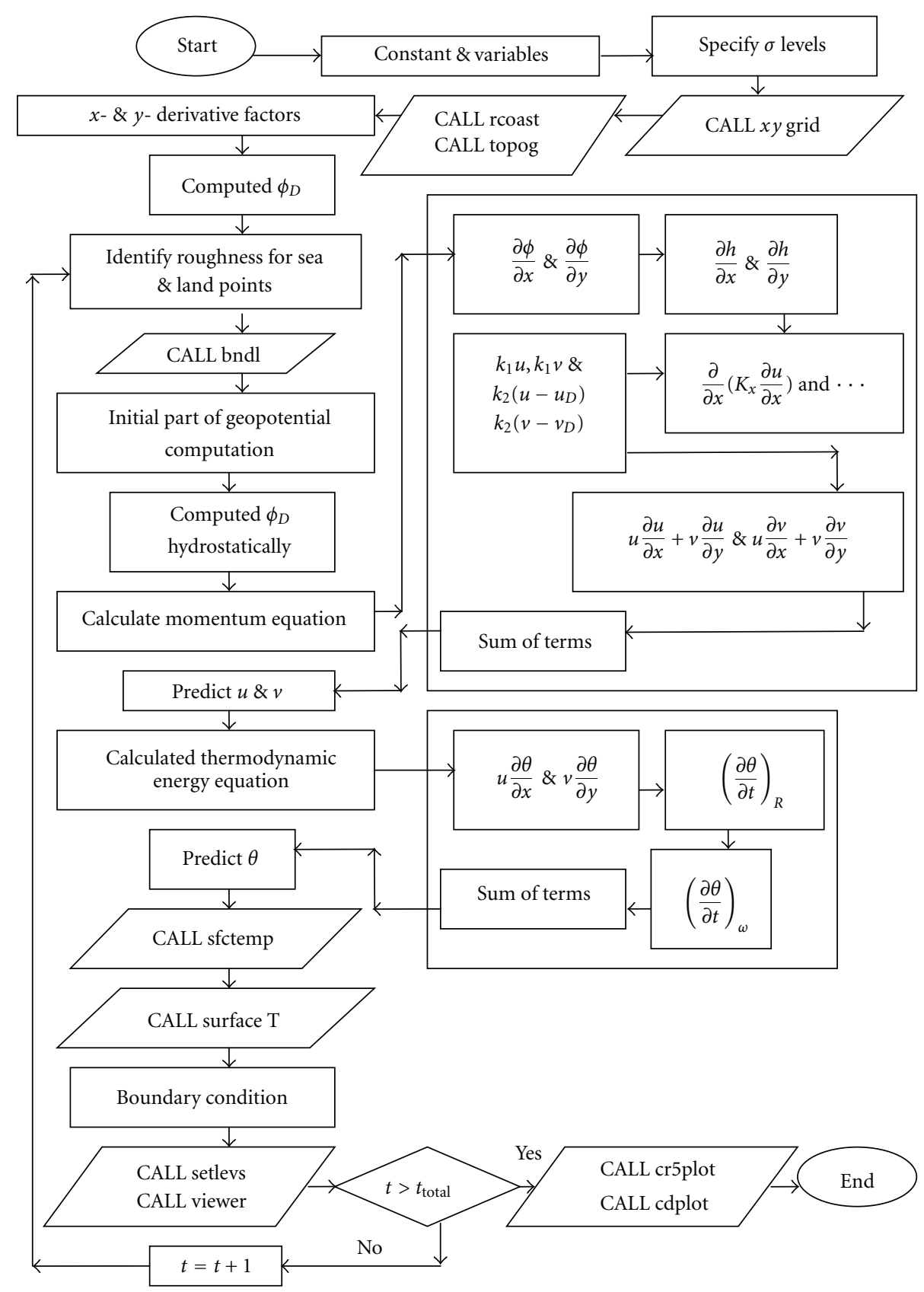

FIGURE 8: Model algorithm.

TABLE 2: Characteristics of land/sea breezes at different days of October 2002.

\begin{tabular}{|c|c|c|c|c|c|c|}
\hline Date & Starting time & Ending time & Durations (Hour) & Speed $(\mathrm{m} / \mathrm{s})$ & Depth $(\mathrm{m})$ & Horizontal extent $(\mathrm{km})$ \\
\hline 2nd & 13 & 21 & 09 & 3.3 & 218 & 33 \\
\hline $3 r d$ & 11 & 21 & 11 & 3.6 & 260 & 36 \\
\hline 8 th & 11 & 21 & 11 & 3.1 & 192 & 31 \\
\hline 12 th & 12 & 21 & 10 & 3.7 & 274 & 37 \\
\hline 28th & 11 & 19 & 09 & 2.2 & 097 & 22 \\
\hline Mean & - & - & 10 & 3.2 & 205 & 32 \\
\hline
\end{tabular}


TABLE 3: Characteristics of land/sea breezes at different days of November 2002.

\begin{tabular}{|c|c|c|c|c|c|c|}
\hline Date & Starting time & Ending time & Durations (Hour) & Speed $(\mathrm{m} / \mathrm{s})$ & Depth $(\mathrm{m})$ & Horizontal extent $(\mathrm{km})$ \\
\hline 4 th & 12 & 21 & 10 & 6.6 & 871 & 66 \\
\hline 10th & 12 & 22 & 11 & 4.3 & 370 & 43 \\
\hline 16 th & 13 & 20 & 08 & 5.9 & 696 & 59 \\
\hline 17 th & 14 & 18 & 05 & 3.9 & 304 & 39 \\
\hline 20th & 15 & 19 & 05 & 4.4 & 387 & 44 \\
\hline Mean & - & - & 7.8 & 5.0 & 500 & 50 \\
\hline
\end{tabular}

TABle 4: Characteristics of land/sea breezes at different days of December 2002.

\begin{tabular}{|c|c|c|c|c|c|c|}
\hline Date & Starting time & Ending time & Durations (Hour) & Speed $(\mathrm{m} / \mathrm{s})$ & Depth (m) & Horizontal extent $(\mathrm{km})$ \\
\hline 19th & 12 & 21 & 10 & 4.4 & 387 & 44 \\
\hline 20th & 13 & 20 & 08 & 1.8 & 65 & 18 \\
\hline 25 th & 11 & 23 & 13 & 4.9 & 480 & 49 \\
\hline 27 th & 16 & 19 & 04 & 6.2 & 769 & 62 \\
\hline 28th & 13 & 22 & 10 & 5.1 & 520 & 51 \\
\hline Mean & - & - & 09 & 4.5 & 405 & 45 \\
\hline
\end{tabular}
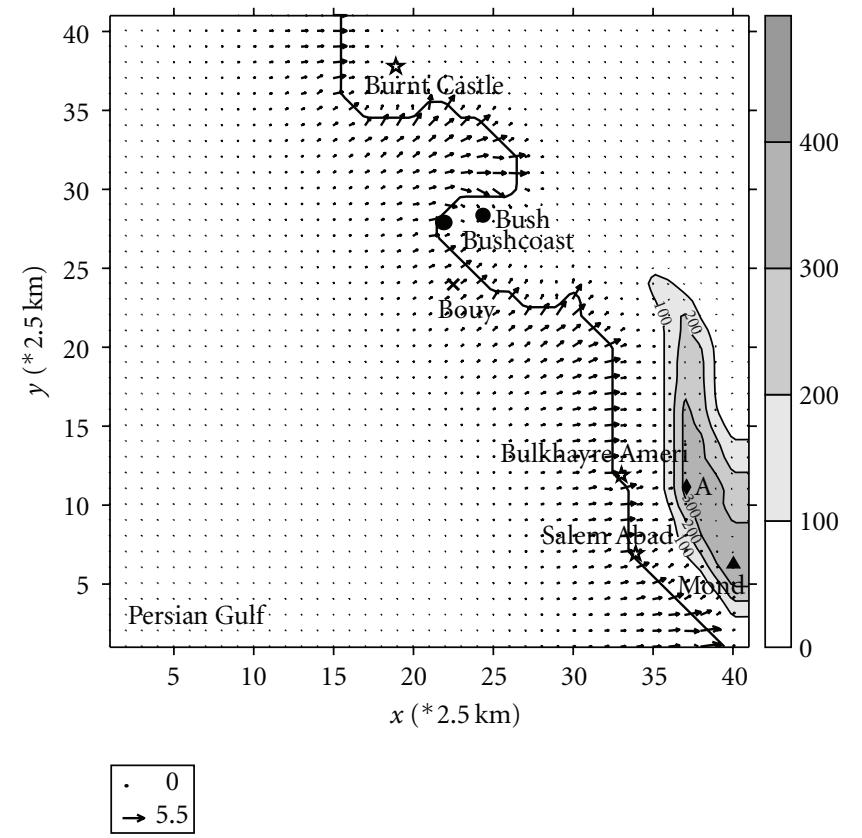

Figure 9: The simulation of wind velocity at $0900 \mathrm{LT}$ on 23 September 2002.

its particular coastal line, its two climatological stations, and its important nuclear power plant. The diurnal variations of wind characteristics in this area, especially near the coastal zone, are normally attributed to the land and sea breeze effects [39]. The topographic map was obtained from The Geographical Armed Force Organization of Iran. It is based on UTM. system by the scale of $1: 500,000$ at the WM, $\mathrm{VM}, \mathrm{WN}$, and $\mathrm{VN}$ sections of this system, between $28^{\circ} 15^{\prime}-$ $29^{\circ} 15^{\prime} \mathrm{E}$ and $50^{\circ} 16^{\prime}-51^{\circ} 15^{\prime} \mathrm{N}$. The Bushehr basin is an almost flat region but has a mountain range, the Mond
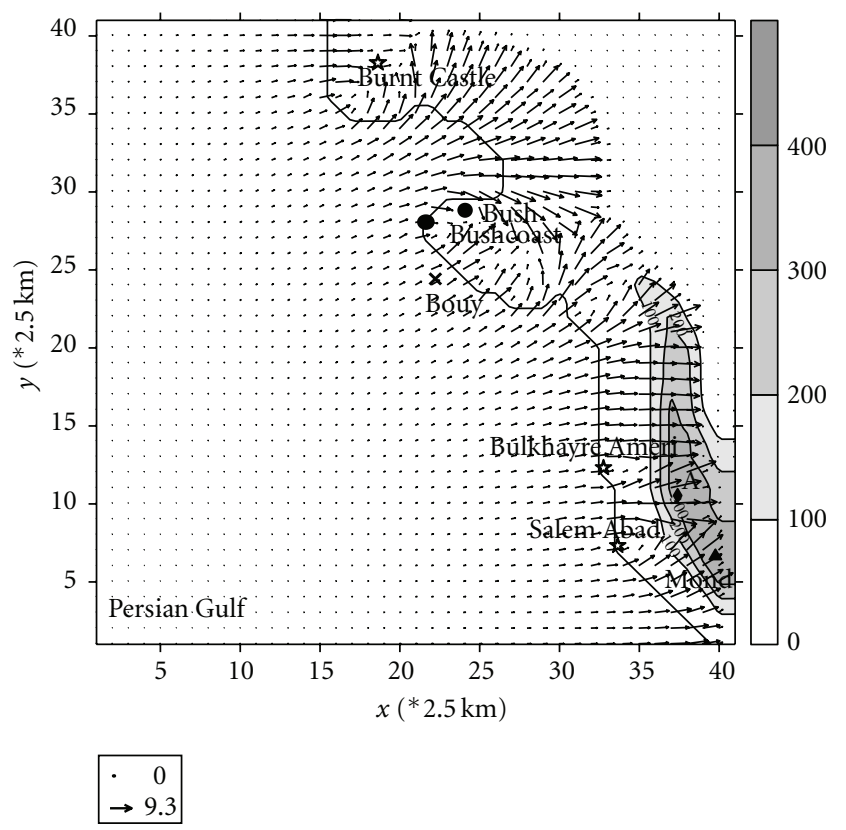

FIgUre 10: The simulation of wind velocity at $1200 \mathrm{LT}$ on 23 September 2002.

Mountains, whose direction is southeast-northwest, (SENW). Consequently, this area may be significantly affected by up- and downslope winds. These up- and downslope winds are valley and mountain breezes, respectively.

Considering Bushehr Climate was the next step. This region has a warm, humid climate, which is affected by the Mediterranean cyclones and the Sudanese lows in the winter, and summer lows in the summer. Wind rose (Figure 1), which is provided from the Bushehr synoptic station, located at $28^{\circ} 59^{\prime} \mathrm{N}$ and $50^{\circ} 50^{\prime} \mathrm{E}$, shows that the predominant wind 

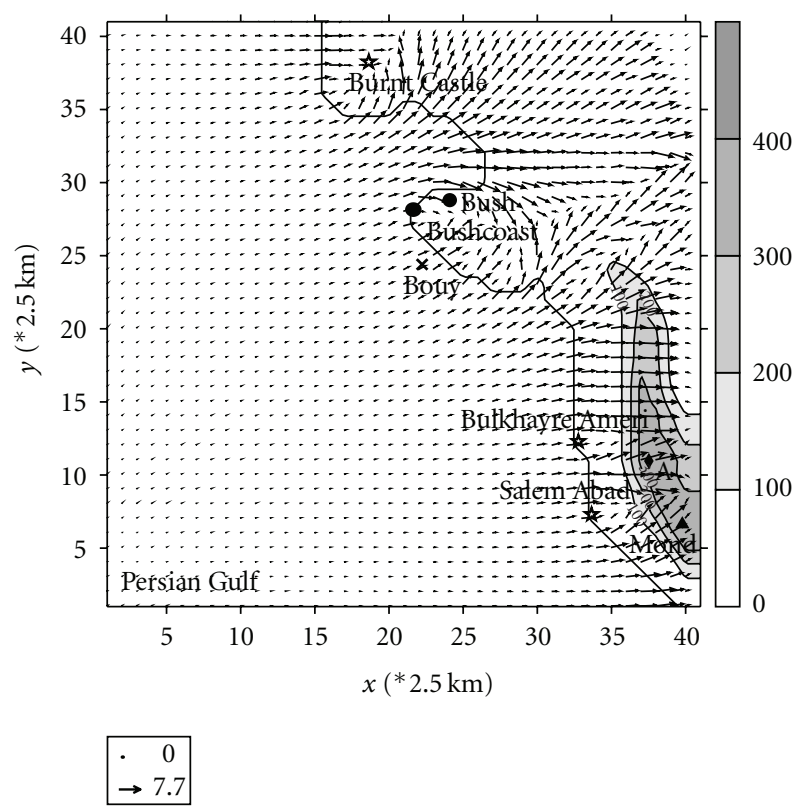

FIgure 11: The simulation of wind velocity at 1500 LT on 23 September 2002.
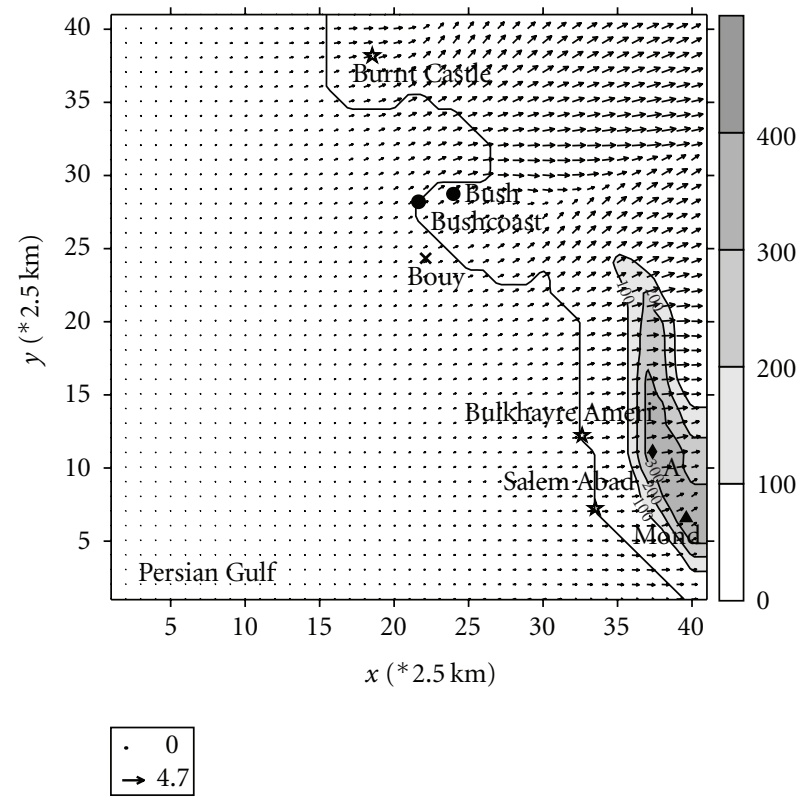

FIGURE 12: The simulation of wind velocity at 1800 LT on 23 September 2002.

is Northwesterly (Shamal wind). Since the prevailing wind can mask the land/sea breeze, the monthly data are required. Observational studies of land/sea breeze, which were provided by The Port and Shipping Organization of Iran, for some selected days of September, October, November, and December (2002) have been shown in Tables 1, 2, 3, and 4, respectively. The tables illustrate that September has the most mean land/sea breezes. Due to this reason, September was selected as an optimum month for modeling. According
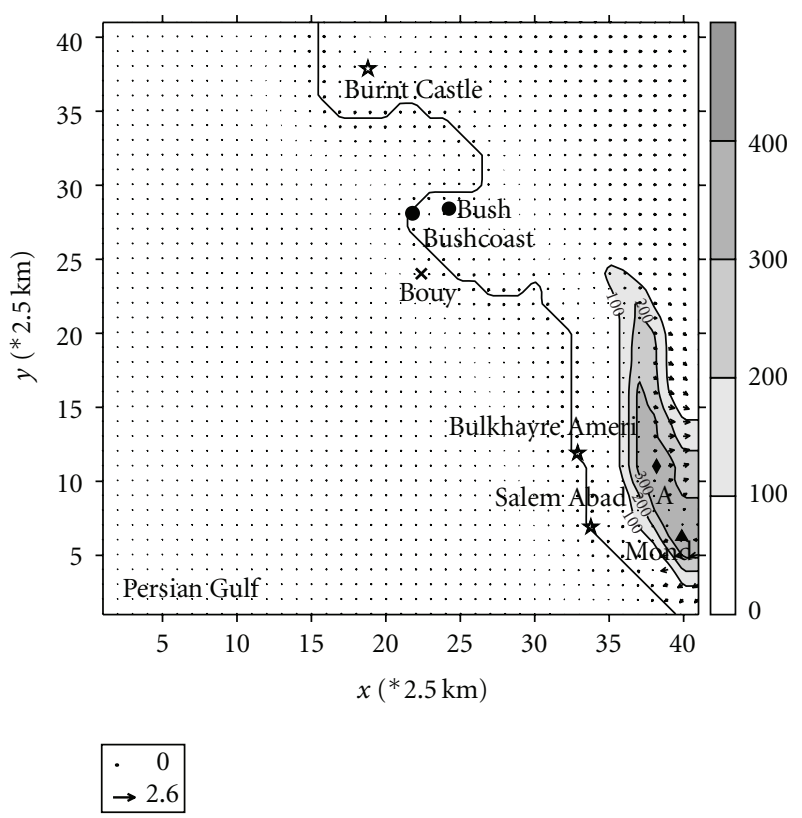

FIgURE 13: The simulation of wind velocity at 2100 LT on 23 September 2002.
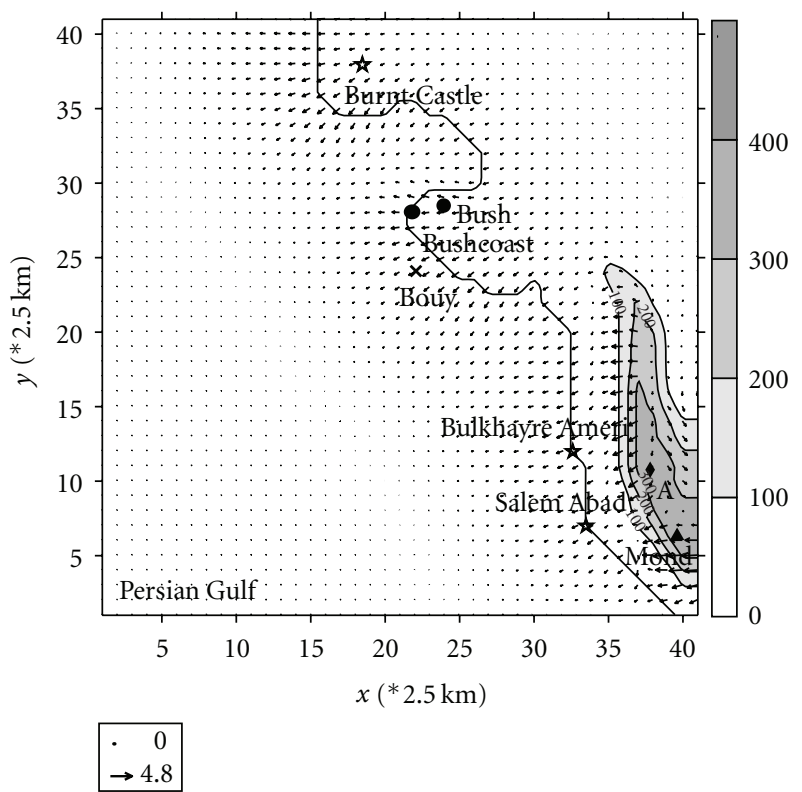

Figure 14: The simulation of wind velocity at $0000 \mathrm{LT}$ on 24 September 2002.

to meteorological data, 23 September 2002 was the best, because there was no prevailing wind before and after that day.

Then, a rectangular grid with a horizontal $2.5 \mathrm{~km}$ grid spacing was used. The vertical domain was $2 \mathrm{~km}$, since breeze could not go higher. (A typical sea breeze has a height of about $1 \mathrm{~km}$. [2]).

The evaluations, $h$, were determined as follows: suppose point, $\mathrm{A}$, if it was on a contour line, its evaluation was 

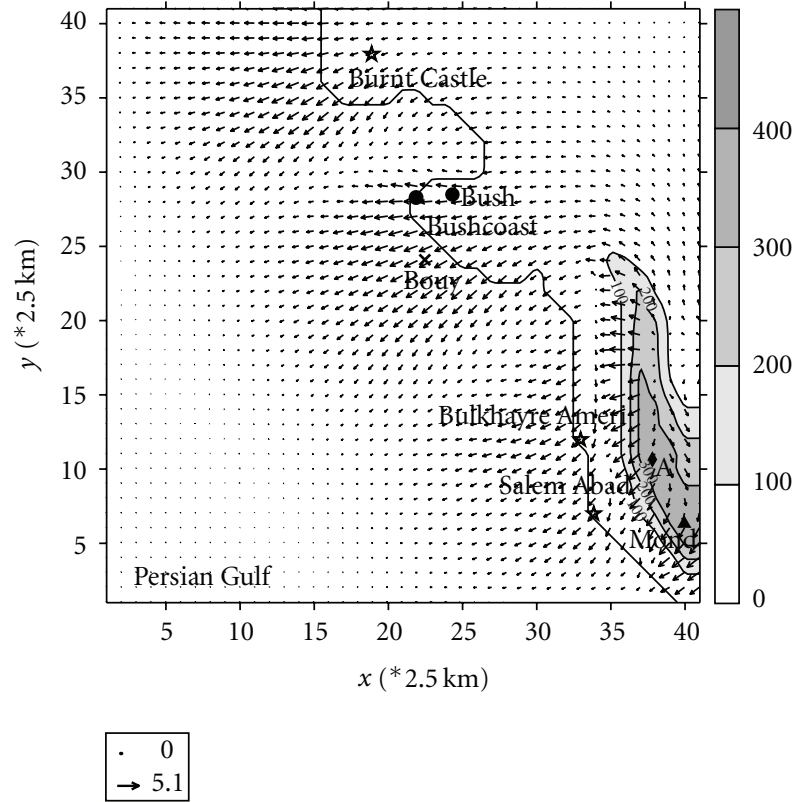

FIgURE 15: The simulation of wind velocity at 0300 LT on 24 September 2002.
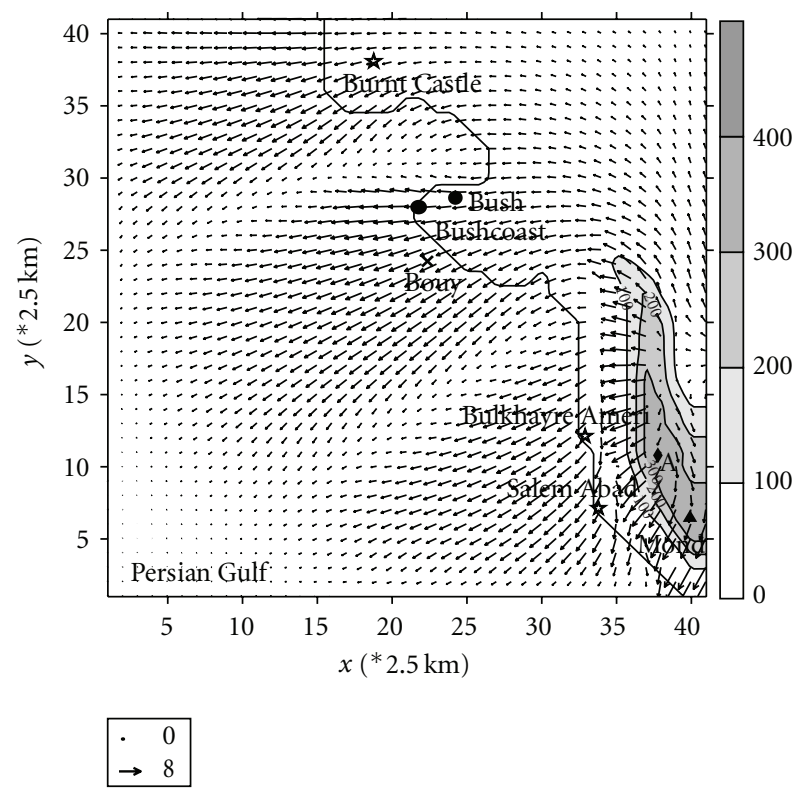

Figure 16: The simulation of wind velocity at 0600 LT on 24 September 2002.

that height of contour line (Figure 2). Otherwise, it was determined by linear interpolation between the nearest contour lines as in the following equation:

$$
h_{\mathrm{A}}=1000 \times \frac{\mathrm{AM}}{\mathrm{MN}}+1200 \times \frac{\mathrm{AN}}{\mathrm{MN}} .
$$

The resulting topography is illustrated in Figure 3.

2.3. Initial and Boundary Conditions. Solving the EsM90 model requires specification of the initial conditions. We set
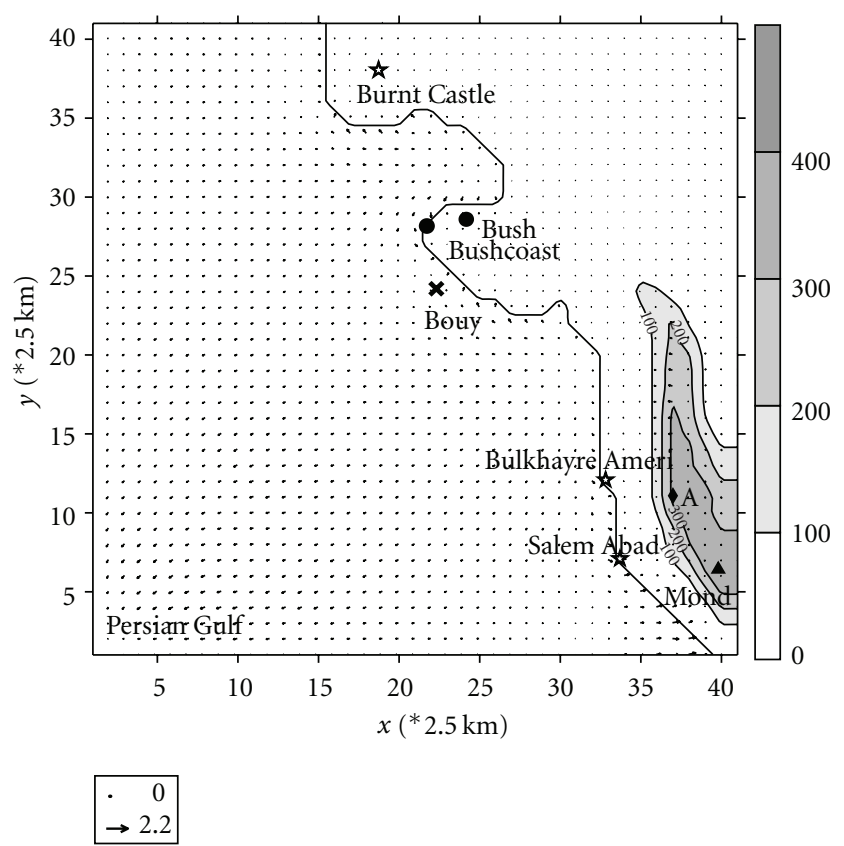

FIgURE 17: The simulation of wind velocity at 0900 LT on 24 September 2002.

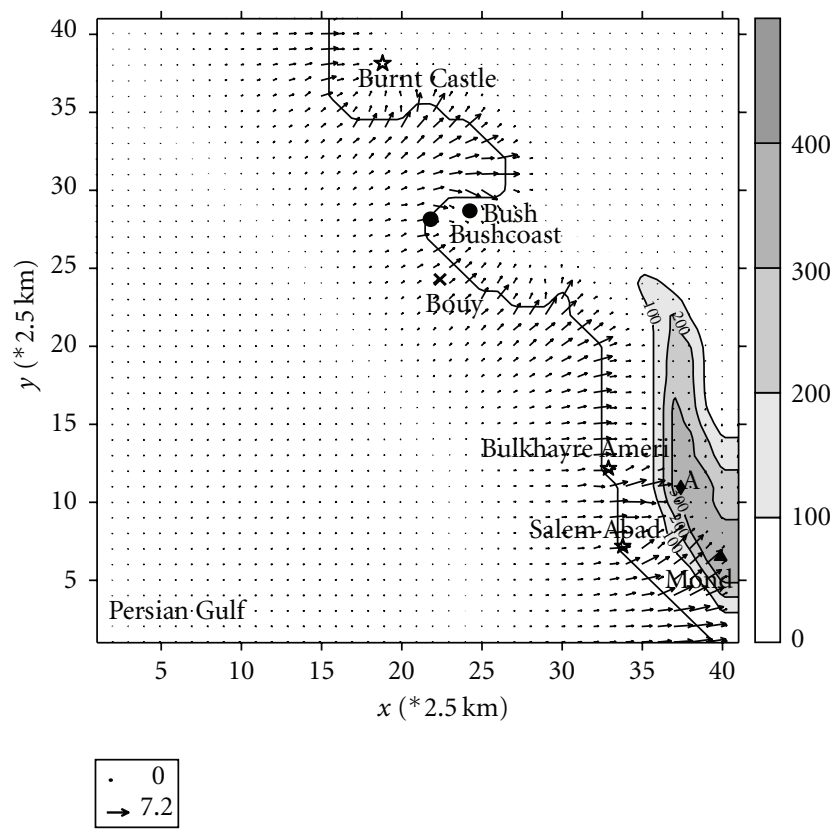

FIGURE 18: The simulation of wind velocity at 1200 LT on 24 September 2002.

$u(x, y), v(x, y), \theta(x, y)$, and $P(x, y)$ to be the value of $u, v$, $\theta$ and $P$ at the surface anemometer level at initial time, $t=0$.

These variables are specified from observations, and so that the initial flow is geostrophically balanced. However, values corresponding to the prevailing flow at the surface anemometer were sometimes chosen. Figures 4 and 5 show the 3-hour wind magnitudes and temperature on September 23, 2002 at Bushehr and its coastal station. As can be seen, 

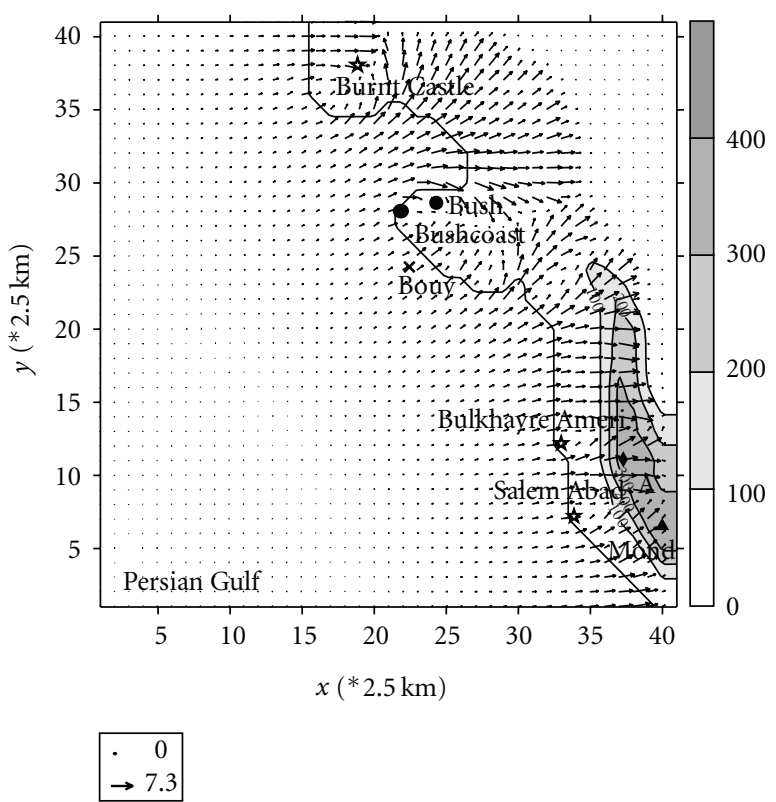

Figure 19: The simulation of wind velocity at 1500 LT on 24 September 2002.
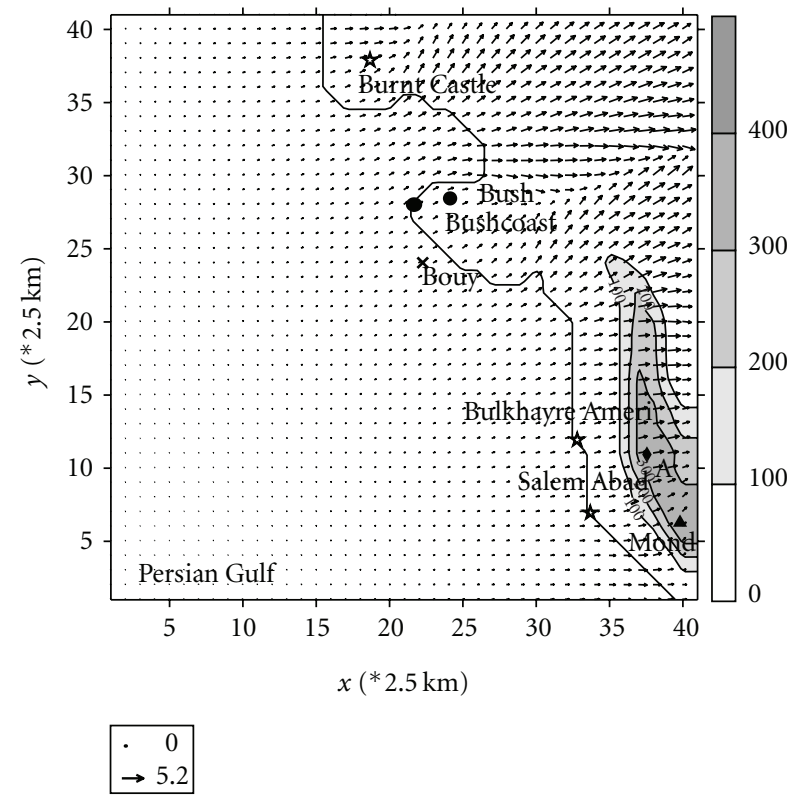

Figure 20: The simulation of wind velocity at 1800 LT on 24 September 2002.

for example, $|\vec{U}|=0.7 \mathrm{~m} / \mathrm{s}, \theta=27.4^{\circ}$ (Bushehr) and $|\vec{U}|=2.2 \mathrm{~m} / \mathrm{s}, \theta=28.6^{\circ}$ (Bushehr coastal station) at 0600 Local Time (LT). In addition, model requires the vertical values of $\theta$ corresponding to the large-scale flow; that is: $\theta(z)=\bar{\theta}(z) ; h \leq z \leq D$ or $\theta(\sigma)=\bar{\theta}(\sigma) ; 0 \leq \sigma \leq 1$. On the basis of Figure $5, \theta(x, y)=26^{\circ} \mathrm{C}=299 \mathrm{~K}$, and, on the basis of Figure $6, P(x, y)=1003 \mathrm{~Pa}$. while the land surface temperature varies with time in this study, the water temperature is held fixed at $33^{\circ} \mathrm{C}$ because there is only a

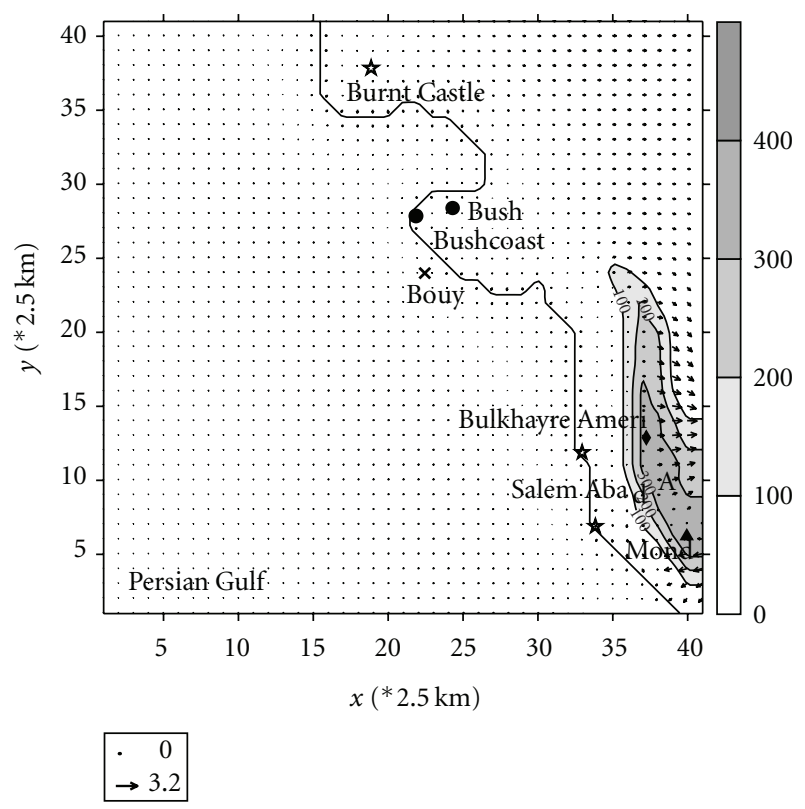

FIgure 21: The simulation of wind velocity at $2100 \mathrm{LT}$ on 24 September 2002.
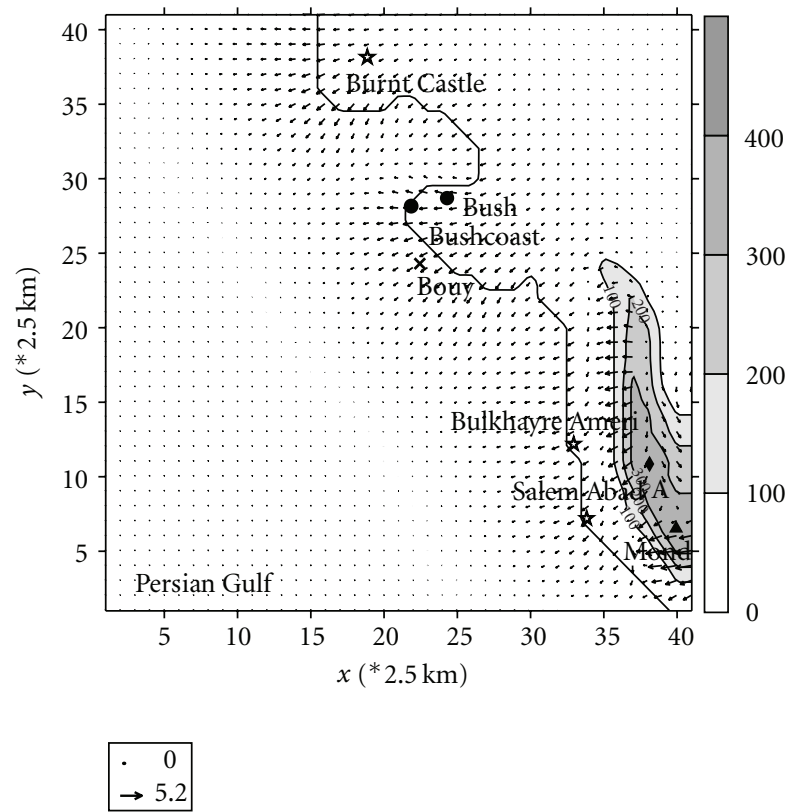

Figure 22: The simulation of wind velocity at $0000 \mathrm{LT}$ on 25 September 2002.

little diurnal variability (Figure 7). The 48-hour simulation starts at 0600 LT, 23 September 2002 and ends at 0600 LT on 25 September. The initial large-scale flow is assumed approximately zero $(u(x, y)=v(x, y)=0.1 \mathrm{~m} / \mathrm{s})$. Recalling that Figure 4 indicates $|\vec{U}|=0.7$ and $2.2 \mathrm{~m} / \mathrm{s}$ at $6: 00$ LT.

Reflective boundaries were applied at open boundaries. Thus for a general quantity, $S$, we have $S_{n}=S_{n-1}$, where $S_{n}$ is the open boundary value and $S_{n-1}$ is its adjacent value at the model domain. On the coastal boundaries, rigid-lid 

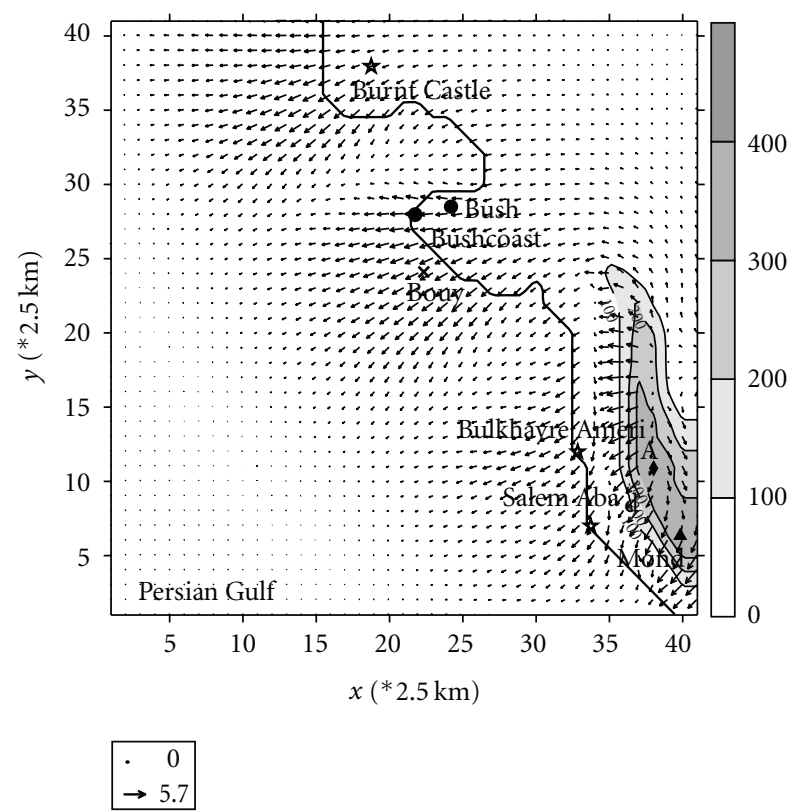

Figure 23: The simulation of wind velocity at $0300 \mathrm{LT}$ on 25 September 2002.
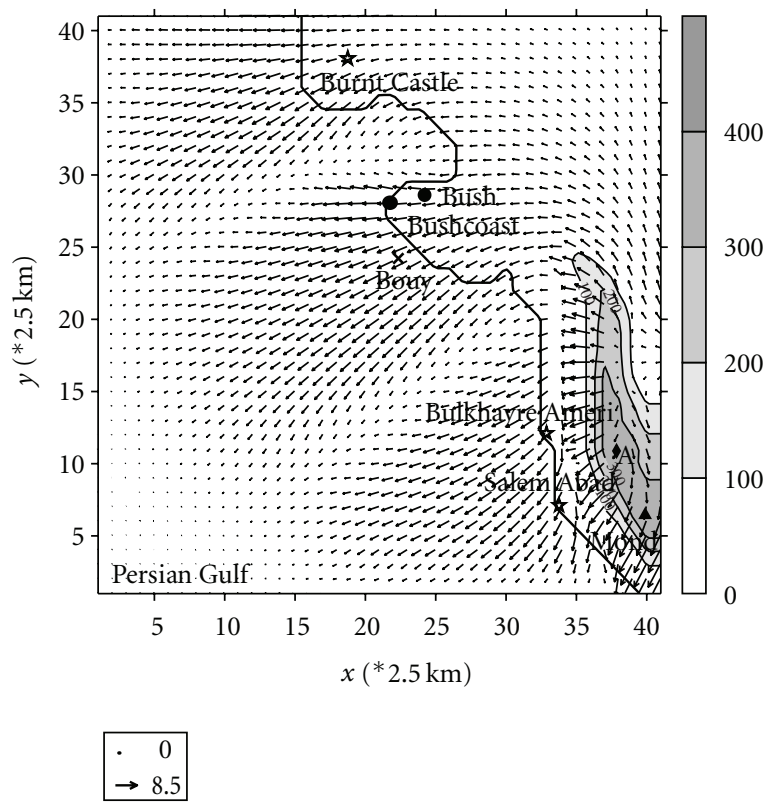

Figure 24: The simulation of wind velocity at 0600 LT on 25 September 2002.

conditions were applied, that is: $S_{n}=0$. At inflow point, values were held fixed. At outflow point, the values are being predicted by the model.

The roughness parameter, $Z_{0}(x, y)$, is taken as $0.1 \mathrm{~m}$ for land and $1 \times 10^{4} \mathrm{~m}$ for water. Surface temperature, $\theta_{s}(x, y, t)$, is taken as $26^{\circ} \mathrm{C}=299 \mathrm{~K}$ (due to Figure 5) for $t=0$, and for $t>0$, it is being predicted by the formula.

2.4. EsM90's Scheme and Constants. We use the same differencing methods which are described at EsM90. Thus, the forward upstream difference technique of EsM90 is used here.

The time step used here is 300 seconds and the 3-hour outputs were printed and analyzed.

The initial values of $u, v$, and $\theta$ were specified so as to be in geostrophic balance. Other parameters and model constants which were used, are $C_{m}=6 \times 10^{-2} ; S=0.5$; $C_{n}=35 ; C_{k}=1 \times 10^{-4} ; C_{B}=0.0 ; C_{R}=3 \times 10^{-5} ; K_{T}=1.0$; $K_{C}=0.05 ; n=0.01 ; Z_{a}=10 \mathrm{~m}$.

The model constant values are determined by numerical experiments in which the model equations were solved by using different values of a particular constant. Then, the particular constant values which gave the most realistic result were selected. The chosen values may not be the optimum ones to be used universally.

2.5. EsM90's Algorithm and the Procedures of the Calculations. The numerical integrations are done by the following stepby-step procedure (See Figure 8 for more details).

(a) Using the specified values of $\theta$ and $\bar{\theta}$ at the surface anemometer level, compute the corresponding value of $\theta^{\prime}$.

(b) Compute the heat term, $Q$.

(c) Using the value of $\theta^{\prime}$, compute $\phi$.

(d) Compute the local tendency terms, $\partial u / \partial t$ and $\partial v / \partial t$.

(e) Using the computed values of $\partial u / \partial t$ and $\partial v / \partial t$, calculate new (forecast) values of $u$ and $v$.

(f) Compute the temperature tendency, $\partial \theta / \partial t$.

(g) Using this value of $\partial \theta / \partial t$, calculate new (forecast) values of $\theta$.

(h) Using the forecast values of $u, v$ and $\theta$ obtained in steps (e) and $(\mathrm{g})$, repeat steps (a) to $(\mathrm{g})$.

Continue this repetitive procedure until the sum of the $\Delta t$ 's is equal to the desired range of the forecast.

The EsM90 program was run on the domain, centered at Bushehr peninsula by a personal computer with Pentium (R) $-4, \mathrm{CPU}=1.70 \mathrm{GHz}$, and RAM = 1 Giga Byte for 48 hours; then, eventually its result was illustrated by Surfer 8 software. The method which was used to make grid files was Kriging.

\section{Results and Discussion}

This study has attempted to produce the land/sea breeze development over the Bushehr peninsula. This peninsula is fairly complicated in that there is a large embayment to the north and coastal mountain to the south. Although this mountain is not very high (less than $400 \mathrm{~m}$ ), the production of up-and downslope winds cannot be ignored. Figures 6-21 illustrate the model's wind vectors at the anemometer level. The tick lines in these figures are the coastlines and thin ones are terrain height (contouring interval $100 \mathrm{~m}$ ). A velocity scale (in $\mathrm{m} / \mathrm{s}$ ), for each figure is provided. The two large solid circles locate the meteorological stations at Bushehr $\left(24^{\circ} \mathrm{N}\right.$, $\left.29^{\circ} \mathrm{E}\right)$ (denoted as Bush) and at the near Bushehr $\left(22^{\circ} \mathrm{N}\right.$, $28^{\circ} \mathrm{E}$ ) (denoted as Bushcoast). The large $\times$ demonstrates the 


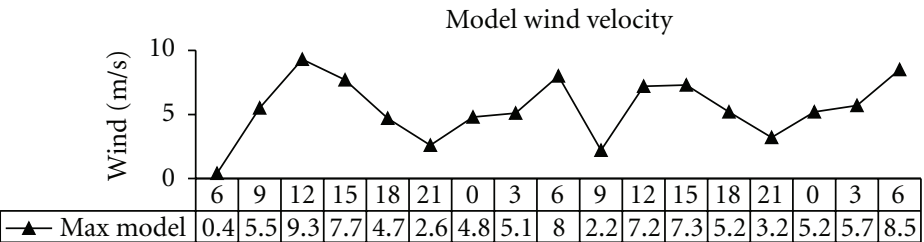

Time (hour)

FIGURE 25: Maximum of wind velocity which is predicted for $0600 \mathrm{LT}$ on 23 September 2002 to 0600 LT on 25 September 2002.

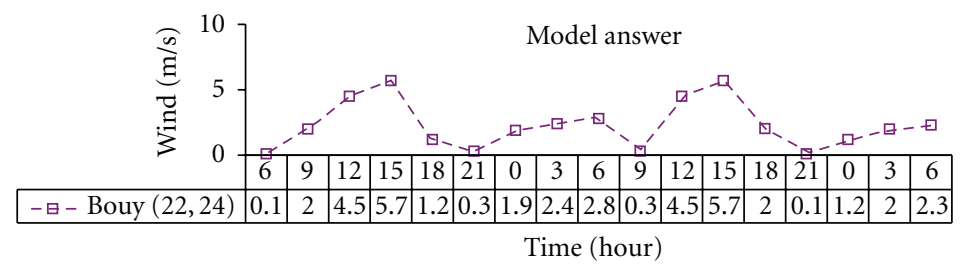

Figure 26: The wind velocity at point Buoy $(22,24)$ for two study day.

location of the meteorological buoy station. The open stars locate three landmarks: Burnt Castle, Bulkhayre Ameri, and Salem Abad. The solid triangle denotes the peak of the Mond Mountains. The capital A is an authority point, $(38,11)$, on the eastern side of the Mond Mountains. This place is adopted to study the model ability to mix land/sea breezes and mountain/valley breezes.

3.1. Start Time and Duration of Breezes. The sea breeze starts at 0900 LT along coastal line (Figure 9) and as sea breeze penetrates into land at 1200 and 1500 LT, upslope winds are also generated (Figures 10 and 11). By looking at Figure 12, we see that wind field is being reduced and at 2100 LT the surface wind is perfectly calm. The observations of the Port and Shipping Organization of Iran, (Table 1), show that $2100 \mathrm{LT} \pm 0100$ is when the land/sea breezes end. So our study using the EsM90 model realistically predicts when the land/sea breezes end. At 0000 LT downslope winds start at Mond Mountain. Land breezes develop at 0300 LT (Figures 15 or 23) and 0600 LT (Figures 16 or 24) over the Persian Gulf and end at 0900 LT (Figure 17). Observational data shows that land breeze ends exactly at 0600 LT (Figure 4), while, this time land breeze model's prediction exists and finishes at $0900 \mathrm{LT}$.

By comparing the two days, it seems the sea breeze extends in to the afternoon. The duration of the sea breeze on the first and second day is about $15 \mathrm{~h}$ and $12 \mathrm{~h}$, respectively, (Figure 25), while the observed duration is about $15 \mathrm{~h}$ (Figure 4). But in both days the sea breeze is finished at 2100 LT (Figure 26). The duration and end time are two important results of this simulation; observational studies similarly indicate it is about 11 to 13 hours at September (Table 1). Parvaresh et al. [39] showed during the 21-day period (15 July-4 August 2000), that sea breezes have finished at 2100 LT. Their data were recorded at the same buoy station indicated by $\times$ in our simulation figures [39]. The prediction duration of the land breeze is $9 \mathrm{~h}$; however the observations of Bushehr Synoptic Station show no land breeze and Bushehr Coastal Station's land breeze's duration is just about $6 \mathrm{~h}$. Thus the model's predictions overpredict the duration of land breeze by about $3 \mathrm{~h}$.

3.2. Intensity and Horizontal Extension. After starting model and by approaching noon, intensity increases so that it reaches a maximum of $9.3 \mathrm{~m} / \mathrm{s}$ at $1200 \mathrm{LT}$ on the 1 st day (Figure 10 ) or $7.3 \mathrm{~m} / \mathrm{s}$ at 1500 LT on the 2 nd day (Figure 19). Then, it decreases by the evening and disappeared at 2100 LT in both days (just small values at the back of the mountain). If we make 1800 LT an exception, it can be said that sea breeze velocity on the 1 st day is stronger than the 2 nd one, while land breeze is reversed. Maximum of land breeze speed is $5.2 \mathrm{~m} / \mathrm{s}$ at $0000 \mathrm{LT}, 5.7 \mathrm{~m} / \mathrm{s}$ at $0300 \mathrm{LT}$, and $8.5 \mathrm{~m} / \mathrm{s}$ at $0600 \mathrm{LT}$, all of them take place on the 2 nd day. When the land breeze ends at $0900 \mathrm{LT}$, just a weak sea breeze with the maximum of $2.2 \mathrm{~m} / \mathrm{s}$ is predicted.

The predicted sea breeze at Bushehr meteorological station is less than the observed wind speed by $1 \mathrm{~m} / \mathrm{s}$ on the average; the predicted land breeze is somewhat greater than the observation (Figures 4 and 27). The maximum predicted sea breeze occurs at 1200 LT while the observed one is three hours later at 1500 LT (Figures 4 and 27), but at the 2nd day is exactly the same.

Parvaresh et al. [39] showed that wind speed at $10 \mathrm{~m}$ above sea level $\left(U_{10}\right)$ varied between 0.34 and $10.38 \mathrm{~m} / \mathrm{s}$ with a characteristic diurnal oscillation. They also resolved wind speed into two components, along and across the shore. Their results show that the wind speed associated with the land breeze is less than $6 \mathrm{~m} / \mathrm{s}$, but that of the sea/land breeze is greater [39]. Although the model simulates a different month and year than when the data were collected, and the observations (as noted in [39]) do not remove the prevailing wind effect from the reported land/sea breeze, the model results show the land breeze $<6 \mathrm{~m} / \mathrm{s}$ at the observations, which is in agreement with the observations. 




Time (hour)

FIgURE 27: The predicted wind velocity at point Bush $(24,29)$ for two study day.

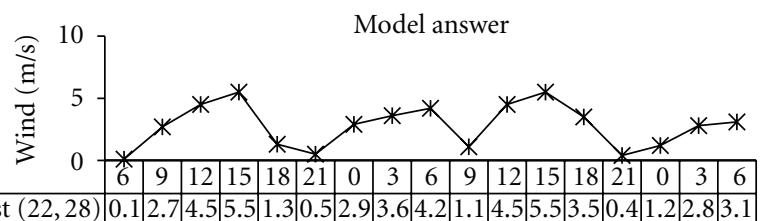

Time (hour)

FIgURE 28: The predicted wind velocity at point Bushcoast $(22,28)$ for two study days.

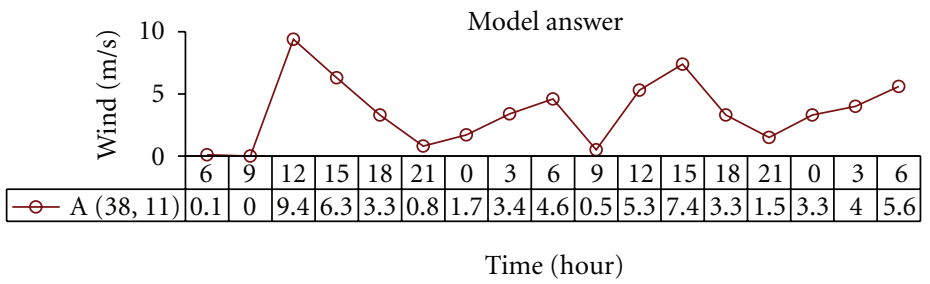

FIGURE 29: The predicted wind velocity at an authority point A $(38,11)$ for two study day.

If we use Bush pint $\left(24^{\circ} \mathrm{N}, 29^{\circ} \mathrm{E}\right.$ or $\left.(24,29)\right)$ as a reference, by 1200 LT on 23 September 2002 (Figure 10), horizontal extension of sea breeze is about $20 \mathrm{~km}$ and doubled by 1500 LT. By 1500 LT on 24 September 2002 (Figure 19), it is about $20 \mathrm{~km}$ in land, whereas land breeze is at about $60 \mathrm{~km}$ at $0600 \mathrm{LT}$ over the sea. Comparing these two days, 2nd day's sea breeze shows a shorter horizontal penetration than the 1st one at the same times, while land breeze is opposite.

Since, sea breeze start at $u=v=0.1 \mathrm{~m} / \mathrm{s}$ on the first day, these values are different on the next day, sea breeze, therefore, starts from the previous land breeze, and this delay to reproducing land/sea breezes influence, both the intensity and horizontal extension, to some extent.

\subsection{The Effect of Coastal Topography. At 1200 LT and 1500 LT} (Figures 13 and 14), a convergence area can be seen over the Bushehr peninsula, and also near Burnt Castle, Bulkhayre Ameri and Salem Abad. Lyons et al. [40] and Nicholls et al. [41] have shown that thunderstorms frequently form near and ahead of sea breeze fronts; so cumulus clouds and thunderstorms are probable at the convergence zones. Convergence zones are not restricted to sea breezes. Two of them are generated at 0300 and 0600 LT over the Persian Gulf when land breezes developed perfectly over the sea.

If we look carefully to the model prediction of breezes at $2100 \mathrm{LT}$, it can be recognized that the maximum velocity values $(2.6 \mathrm{~m} / \mathrm{s}$ on 23 September 2002 and $3.2 \mathrm{~m} / \mathrm{s}$ on 24
September 2002) is returning to the values back of the mountain.

One gets the impression from the model results (Figures 9-24) that the land/sea breeze is less pronounced along the coast at the northern boundary, and that this breeze is quite pronounced along the southern coast in the region near Mond Mountain. The predicted winds at point A on the lee side of mount (Figure 29) show that the land/sea breeze is generally stronger there than at the Bushehr and Bushehr Coastal stations (Figures 27 and 28).

\section{Conclusion}

In brief, the EsM90 on Bushehr has some defects to reduce enough as breeze goes far in land or sea. Furthermore, some deviations occur on the prediction of breeze duration, although it is much more powerful to bring a good simulation based on coastal shape and approximately real values (about $0-3 \mathrm{~m} / \mathrm{s}$ difference). The model also combines land/sea breezes by mountain/valley breezes very well at the side near the coast but be defeated to produce separately mountain/valley breezes as can be seen at the back of Mond Mountain.

The duration of the sea breeze on the first and second day is about 15 and 12 hours, respectively. The model predicts well the land breeze at the Bushehr coastal station.

The land/sea breeze is less pronounced along the coast at the northern boundary, and that this breeze is quite 
pronounced along the southern coast in the region near Mond Mountain.

In the end, a satisfied wind field is produced which can show up- and downslope winds in addition to land/sea breezes.

\section{Acknowledgments}

The study was supported by the Department of Physical Oceanography, Khorramshahr Marine Science and Technology University, Khoramshahr, Iran. The authors would like to thank Professor G. Weatherly (Florida State University) for reading the paper and his constructive comments. Finally, the authors are most grateful to two anonymous reviewers for many detailed and thoughtful comments.

\section{References}

[1] J. Neumann, "The sea and land breezes in the classical Greek literature," Bulletin of the American Meteorological Society, vol. 54, no. 1, pp. 5-8, 1973.

[2] T. Beer, Environmental Oceanography, CRC Press, Boca Raton, Fla, USA, 2nd edition, 1996.

[3] S. A. Hsu, Coastal Meteorology, Academic Press, New York, NY, USA, 1988.

[4] R. W. Arritt, "Effects of the large-scale flow on characteristic features of the sea breeze," Journal of Applied Meteorology, vol. 32, no. 1, pp. 116-125, 1993.

[5] B. W. Atkinson, Meso-scale Atmospheric Circulations, Academic Press, London, UK, 1981.

[6] J. A. Frizzola and E. L. Fisher, "A series of sea-breeze observations in the New York city area," Journal of Applied Meteorology, vol. 2, no. 6, pp. 722-739, 1963.

[7] R. Wexler, "Theory and observations of land and sea breeze," Bulletin of the American Meteorological Society, vol. 27, pp. 272-287, 1946.

[8] S. T. Gille, S. G. L. Smith, and N. M. Statom, "Global observations of the land breeze," Geophysical Research Letters, vol. 32, no. 5, article L05605, pp. 1-4, 2005.

[9] J. F. Miao, L. J. M. Kroon, J. Vilà-Guerau de Arellano, and A. A. M. Holtslag, "Impacts of topography and land degradation on the sea breeze over eastern Spain," Meteorology and Atmospheric Physics, vol. 84, no. 3-4, pp. 157-170, 2003.

[10] M. M. Millán, E. Mantilla, R. Salvador et al., "Ozone cycles in the western Mediterranean basin: interpretation of monitoring data in complex coastal terrain," Journal of Applied Meteorology, vol. 39, no. 4, pp. 487-508, 2000.

[11] J. E. Simpson, Sea Breeze and Local Winds, Cambridge University Press, Cambridge, UK, 1994.

[12] M. Segal and R. W. Arritt, "Nonclassical mesoscale circulations caused by surface sensible heat- flux gradients," Bulletin of the American Meteorological Society, vol. 73, no. 10, pp. 15931604, 1992.

[13] M. M. Verstraete, "Defining desertification: a review," Climatic Change, vol. 9, no. 1-2, pp. 5-18, 1986.

[14] P. Alpert, M. Kusuda, and N. Abe, "Anticlockwise rotation, eccentricity and tilt angle of the wind hodograph. Part II: an observational study," Journal of the Atmospheric Sciences, vol. 41, no. 24, pp. 3568-3583, 1984.

[15] M. Kusuda and P. Alpert, "Anti-clockwise rotation of the wind hodograph. Part I: theoretical study," Journal of the Atmospheric Sciences, vol. 40, no. 2, pp. 487-499, 1983.
[16] H. Yan and R. A. Anthes, "The effect of variations in surface moisture on mesoscale circulations," Monthly Weather Review, vol. 116, no. 1, pp. 192-208, 1988.

[17] J. F. Mahfouf, E. Richard, and P. Mascart, "The influence of soil and vegetation on the development of mesoscale circulations," Journal of Applied Meteorology and Climatology, vol. 26, pp. 1483-1495, 1987.

[18] W. L. Physick, "Numerical experiments on the inland penetration of the sea breeze," Quarterly Journal of the Royal Meteorological Society, vol. 106, no. 450, pp. 735-746, 1980.

[19] J. M. Medlin and P. J. Croft, "A preliminary investigation and diagnosis of weak shear summertime convective initiation for extreme southwest Alabama," Weather and Forecasting, vol. 13, no. 3, pp. 717-728, 1998.

[20] N. F. Laird, D. A. R. Kristovich, R. M. Rauber, H. T. Ochs, and L. J. Miller, "The cape canaveral sea and river breezes: kinematic structure and convective initiation," Monthly Weather Review, vol. 123, pp. 2942-2956, 1995.

[21] R. A. Pielke, "A three-dimensional numerical model of the sea breezes over south Florida," Monthly Weather Review, vol. 102, pp. 115-139, 1974.

[22] D. D. Reible, J. E. Simpson, and P. F. Linden, "The sea breeze and gravity current frontogenesis," Quarterly Journal of the Royal Meteorological Society, vol. 119, no. 509, pp. 1-16, 1993.

[23] H. Yoshikado, "Vertical structure of the sea breeze penetrating through a large urban complex," Journal of Applied Meteorology, vol. 29, no. 9, pp. 878-891, 1990.

[24] R. M. Wakimoto and N. T. Atkins, "Observations of the seabreeze front during CaPE. Part I: single-Dopper, satellite, and cloud photogrammetry analysis," Monthly Weather Review, vol. 122, no. 6, pp. 1092-1114, 1994.

[25] J. M. Intrieri, C. G. Little, W. J. Shaw, R. M. Banta, P. A. Durkee, and R. M. Hardesty, "The land/sea breeze experiment (LASBEX)," Bulletin of the American Meteorological Society, vol. 71, no. 5, pp. 656-664, 1990.

[26] S. Mitsumoto, H. Ueda, and H. Ozoe, "A laboratory experiment on the dynamics of the land and sea breeze," Journal of the Atmospheric Sciences, vol. 40, no. 5, pp. 1228-1240, 1983.

[27] G. A. Dalu and R. A. Pielke, "An analytical study of the sea breeze," Journal of the Atmospheric Sciences, vol. 46, no. 12, pp. 1815-1825, 1989.

[28] M. A. Estoque, "A surface mesoscale wind model for complex terrain," Atmosfera, vol. 3, no. 3, pp. 203-216, 1990.

[29] M. A. Estoque, "The sea breeze as a function of the prevailing synoptic situation," Journal of the Atmospheric Sciences, vol. 19, pp. 244-250, 1992.

[30] A. Ding, T. Wang, M. Zhao, T. Wang, and Z. Li, "Simulation of sea-land breezes and a discussion of their implications on the transport of air pollution during a multi-day ozone episode in the Pearl River Delta of China," Atmospheric Environment, vol. 38, no. 39, pp. 6737-6750, 2004.

[31] P. Hyder, J. H. Simpson, and S. Christopoulos, "Sea-breeze forced diurnal surface currents in the Thermaikos Gulf, northwest Aegean," Continental Shelf Research, vol. 22, no. 4, pp. 585-601, 2002.

[32] C. Chen and L. Xie, "A numerical study of wind-induced, near-inertial oscillations over the Texas-Louisiana shelf," Journal of Geophysical Research, vol. 102, no. C7, pp. 15583-15593, 1997.

[33] J. J. O’Brien, R. M. Clancy, A. J. Clarke et al., "Upwelling in the ocean : twoand three dimensional models of upper ocean dynamics and variability," in Modelling and Prediction of the Upper Layers of the Ocean, E. B. Kraus, Ed., pp. 178-228, Pergamon Press, Oxford, UK, 1977. 
[34] P. D. Craig, "A model of diurnally forced vertical current structure near $30^{\circ}$ latitude," Continental Shelf Research, vol. 9, no. 11, pp. 965-980, 1989.

[35] P. D. Craig, "Constant-eddy-viscosity models of vertical structure forced by periodic winds," Continental Shelf Research, vol. 9, no. 4, pp. 343-358, 1989.

[36] L. K. Rosenfeld, "Diurnal period wind stress and current fluctuations over the continental shelf off northern California," Journal of Geophysical Research, vol. 93, pp. 2257-2276, 1988.

[37] J. Smagorinsky, S. Manabe, and J. L. Holloway, "Numerical results from a nine-level general circulation model of atmosphere," Monthly Weather Review, vol. 93, pp. 727-742, 1965.

[38] J. F. Louis, M. Tiedtke, and J. F. Golga, "A short history of PBL parameterization at ECMWF," in Proceedings of the ECMWF Workshop on Planetary Boundary Layer Parameterization, Reading Berkshire, UK, 1981.

[39] A. Parvaresh, S. Hassanzadeh, and M. H. Bordbar, "Statistical analysis of wave parameters in the north coast of the Persian Gulf," Annales Geophysicae, vol. 23, no. 6, pp. 2031-2038, 2005.

[40] W. A. Lyons, R. L. Walko, M. E. Nicholls, R. A. Pielke, W. R. Cotton, and C. S. Keen, "Observational and numerical modeling investigations of Florida thunderstorms generated by multi-scale surface thermal forcing," in Proceedings of the 5th Conference on Mesoscale Processes, pp. 85-90, AMS, Atlanta, Ga, USA, 1992.

[41] M. E. Nicholls, R. A. Pielke, and W. R. Cotton, "A two-dimensional numerical investigation of the interaction between sea breezes and deep convection over the Florida Peninsula," Monthly Weather Review, vol. 119, no. 2, pp. 298323, 1991. 

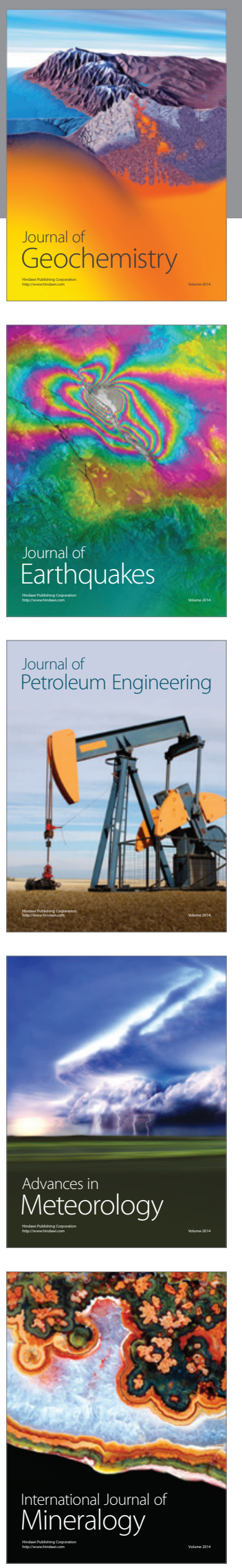
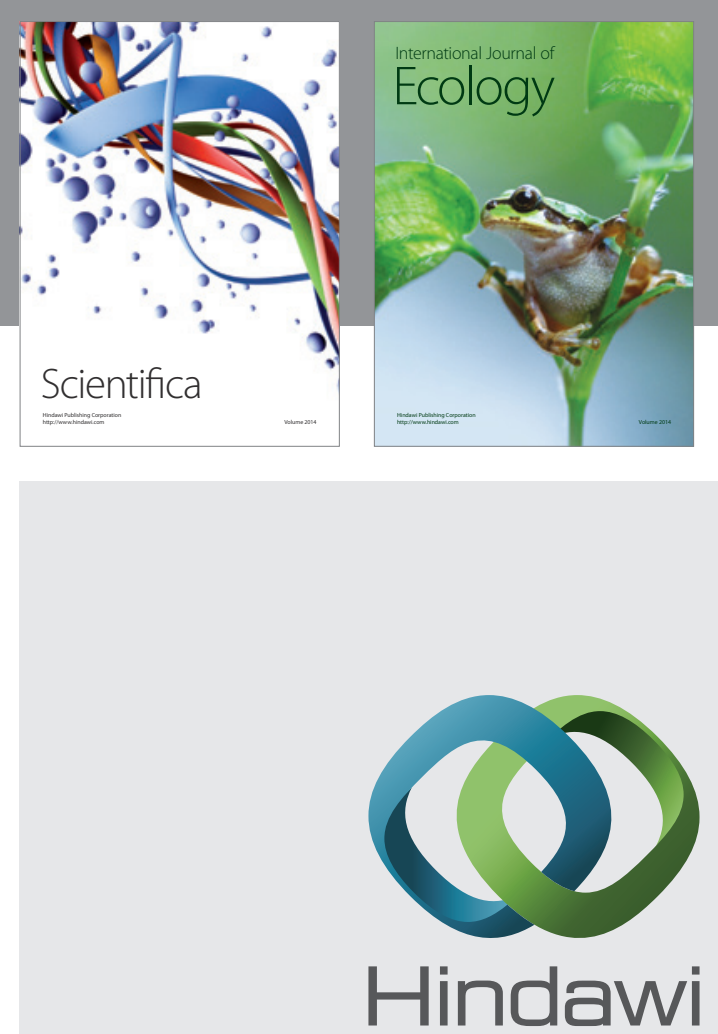

Submit your manuscripts at http://www.hindawi.com
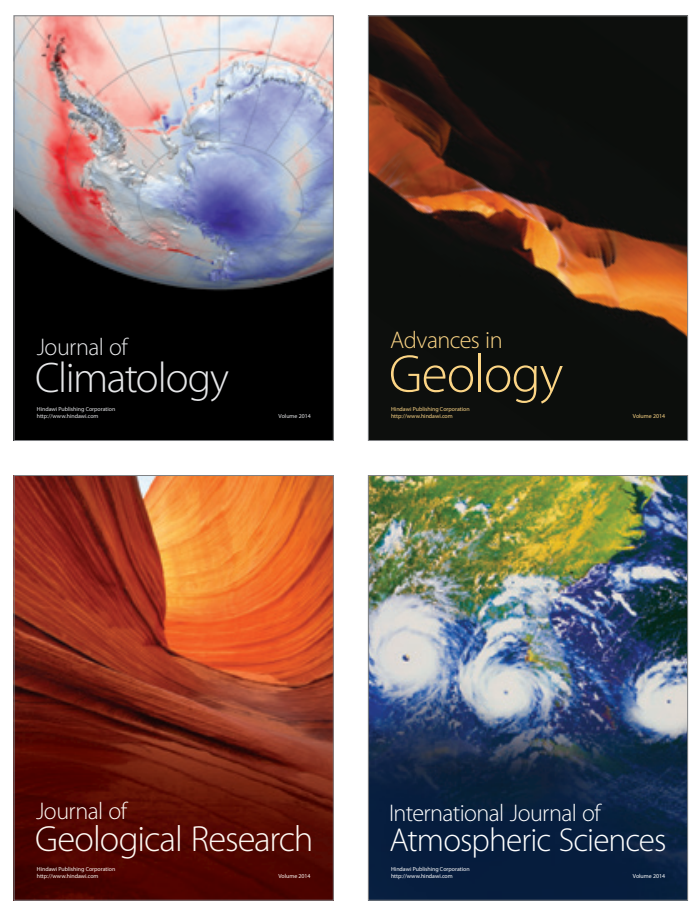
